\title{
DESIGUALDADES NAS TRANSIÇÕES PARA A VIDA ADULTA NO BRASIL (1996 E 2008)
}

No Brasil, a passagem do milênio também foi um momento de virada demográfica importante para a população jovem. Em I996, a coorte de idade entre I2 e 30 anos contava com 60 milhões de pessoas, sendo responsável por um pouco mais de um terço da população (35\%). Uma coorte mais nova entre I 2 e 30 anos em 2008, que tinha entre i e I8 anos em I996, contava com $58 \mathrm{mi}$ lhões, o que também correspondia a cerca de um terço da população (33\%). Em termos relativos, a população jovem fora maior em períodos anteriores. Em números absolutos, no entanto, nunca foi tão grande quanto durante as décadas de 1990 e 2000. O que é ainda mais impressionante é que, devido às taxas de fecundidade e mortalidade, a população de jovens nunca mais voltará a ser tão grande. Há uma tendência inexorável de envelhecimento da população brasileira (IBGE, 2008). Essa situação é uma consequência do que alguns demógrafos chamam da "onda de jovens" que começou a crescer nas décadas de I960 e I970 (Bercovich, I992; Wajnman, I998).

Essa duas enormes coortes de jovens começaram a entrar na vida adulta durante os anos I980, I990 e 2000, décadas marcadas por forças opostas. Por um lado, estagnação econômica e altos níveis de desigualdade de renda e, por outro, avanços nos direitos civis e benefícios tais como a expansão do sistema educacional, aumento do acesso ao sistema de saúde, maior regulamentação do mercado de trabalho e mais proteção social por parte do Estado. Estagnação econômica e desigualdades implicam mais heterogeneidade e 
diferenças nos padrões de transição para a vida adulta, ou seja, são forças que levam indivíduos com características socioeconômicas distintas a fazerem transições para a vida adulta em momentos diferentes do ciclo de vida. Em contrapartida, a expansão da cidadania e dos benefícios sociais funcionam como um forte mecanismo de padronização, levando a uma homogeneização dos padrões de transição entre diferentes grupos sociais, ou seja, diminui a diferença entre os padrões de transição para vida adulta de jovens com diferentes origens socioeconômicas. O principal objetivo deste artigo é localizar os mecanismos institucionais relacionados à família, ao sistema escolar e ao mercado de trabalho através dos quais a desigualdade e a expansão dos benefícios sociais contribuíram para a criação de diferentes padrões de transição para a vida adulta. As análises são baseadas em dados referentes a duas coortes de idade sucessivas: a primeira, nascida entre I966 e I984, representando jovens entrando no mercado de trabalho, se casando e se tornando pais entre a metade dos anos I980 e I996; e a segunda, nascida entre 1978 e I996, fazendo as transições para a vida adulta entre meados dos anos I990 e 2008.

Este grande grupo de jovens, representado no presente artigo por estas duas coortes de idade, tem sido objeto de preocupações políticas e acadêmicas desde o fim da década de I99o (Berquó, I998; Silva, 2002; Cano, 2003; Hasenbalg, 2003; Barros, 2005; Berquó, 2005; Brandão, 2006). Em geral, estes estudos abordam questões específicas e não procuram tratar da questão das transições para a vida adulta. ${ }^{\mathrm{I}}$ Partindo de uma abordagem mais analítica, procuro estudar a relação, o tempo e a estratificação nas transições marcadas pela entrada no mercado de trabalho, pela constituição do primeiro domicílio autônomo (independente dos pais), pelo primeiro casamento e pelo nascimento do primeiro filho (para mulheres apenas). Para tanto, uso modelos estatísticos para definir fatores correlacionados às transições no que denomino de esfera produtiva (trabalho e escolaridade) e esfera reprodutiva (domicílio, casamento e maternidade) da vida. Alguns trabalhos anteriores também adotaram uma perspectiva analítica para entender transições para o mercado de trabalho (Corseuil, 200I) e para o casamento e a maternidade (Oliveira, 2006). Minhas análises se diferenciam destes trabalhos na medida em que estudo conjuntamente as esferas produtiva e reprodutiva da vida dos jovens. Além disso, uso dois bancos de dados que contêm informações sobre a família de origem dos jovens que não moram mais com seus pais (as pesquisas usuais do IBGE não incluem essa informação pelo menos desde I996), o que permite analisar de forma direta o efeito das condições socioeconômicas e culturais das famílias de origem nos padrões de transição para a vida adulta dos jovens. Parto da ideia de que essa abordagem integrada é essencial para entender melhor os mecanismos que caracterizam a entrada na vida adulta. Em outras palavras, acredito que a perspectiva adotada neste artigo pode ajudar a descrever a transição para a vida adulta no Brasil levando em conta, por um lado, 
os contextos institucionais do mercado de trabalho, do sistema educacional e da família; e, por outro, as condições socioeconômicas e a estrutura das desigualdades que caracterizaram o Brasil desde meados da década de I980 até a década de 2000 .

Este artigo está organizado da seguinte forma: na próxima seção descrevo as principais características históricas e institucionais da sociedade brasileira desde os anos I980; em seguida, descrevo os dados, os modelos e as variáveis usadas. Depois apresento os principais resultados sobre transições para a vida adulta nas esferas produtiva (trabalho e escola) e reprodutiva (domicílio próprio, casamento e maternidade). Ao final, apresento algumas conclusões mais gerais.

\section{CONTEXTO EM QUE SE DERAM AS TRANSIÇÕES \\ Condições socioeconômicas e característica das desigualdades}

Entre os anos I980 e 2000, quando as duas coortes que utilizo nesta seção estavam entrando na vida adulta, o Brasil experimentou, primeiro, um período de estagnação e crise econômica, e depois, nos anos 2000, iniciou-se timidamente um processo de crescimento da economia. Independentemente destas melhoras no final do período, nestas três décadas o Brasil quase não cresceu (a média de crescimento do PIB entre I98I e I999 foi de I,9\%, e de 2000 até 20 Io foi em torno de 3,8\%). Embora tenha permanecido muito alta ao longo de todo o período, a desigualdade de renda começou a declinar a partir de I994 e, mais intensamente, nos anos 2000 (em I996, o coeficiente de Gini era de 0,602 e, em 2010, era de 0,530). A população abaixo da linha de pobreza diminuiu de forma mais acentuada e significativa, primeiro em I994 e, depois, nos anos 2000. Em I993, cerca de 35\% da população estava abaixo da linha de pobreza; esse número diminuiu para $28 \%$ em I995, permaneceu neste patamar até 2003 , e diminuiu para cerca de I2\% em 2012. Embora o desemprego dos jovens não fosse muito alto, a economia informal crescia rapidamente nos anos I980 e I990, e começou a diminuir nos anos 2000. Em I990, por exemplo, $52 \%$ da força de trabalho urbana estava no setor informal, porcentagem que cresceu para $57 \%$ em 2000, e diminuiu para $47 \%$ em 20r2. Além disso, as décadas I980 e I990 foram marcadas por níveis extremamente altos de inflação, que chegava a 50\% durante os meses mais críticos, problema que foi resolvido com o Plano Real, em I994. Embora a inflação fosse ruim para toda a população, ela afetava mais fortemente os pobres que não tinham meios bancários para proteger seus salários. Só as pessoas mais ricas tinham acesso a contas bancárias que indexavam o dinheiro para que este não perdesse totalmente seu valor.

Um aspecto especialmente importante para entender os padrões de transição para a vida adulta no Brasil é a estrutura da desigualdade. Como é 
de conhecimento geral, a desigualdade no Brasil é caracterizada pela concentração no topo e menos diferença entre o meio e a parte inferior da distribuição de renda. Em I999, por exemplo, os I0\% mais ricos detinham um terço da renda total, enquanto os $50 \%$ mais pobres detinham apenas um décimo da renda disponível. No topo estavam principalmente profissionais e administradores com diplomas universitários e vivendo nos melhores bairros das regiões urbanas. É muito provável que os filhos destas famílias mais ricas tenham seguido padrões de transição para a vida adulta caracterizados por períodos longos de permanência no sistema educacional, entrada no mercado de trabalho depois de terminar os estudos, ou pelo menos durante o período em que estavam na universidade, e tenham se casado ou começado a formar suas famílias próprias mais tardiamente no ciclo de vida. Na base da pirâmide estão tipicamente os trabalhadores manuais e nos serviços de baixa qualificação (por exemplo, vendedores de rua, empregados domésticos etc.). Estes trabalhadores com baixa renda e pouca qualificação educacional precisam, frequentemente, que seus filhos jovens e até crianças trabalhem para complementar a renda familiar. Consequentemente, os filhos dos trabalhadores de baixa renda sofrem mais pressão para deixar a escola e começar a trabalhar mais cedo em seus ciclos de vida. Entre os jovens mais pobres a formação de novas famílias também deve ter ocorrido mais cedo. A gravidez na adolescência, por exemplo, é mais frequente entre os pobres. Tendo em vista que as pessoas no meio da distribuição, que hoje em dia têm sido definidas como "nova classe média", estão mais próximas em termos econômicos dos mais pobres do que dos mais ricos, é provável que sigam padrões de transição semelhantes aos destes mais pobres. Em suma, nas décadas de I980, I990 e 2000 a estrutura de desigualdades no país permaneceu sendo marcada por uma dualidade dividindo os mais ricos do resto da população. Consequentemente, os efeitos das condições socioeconômicas das famílias de origem (definidas nas análises desenvolvidas neste artigo por ocupação e educação dos pais) têm provavelmente um efeito forte nas esferas produtiva e reprodutiva da transição para a vida adulta.

\section{Características institucionais}

Embora os anos I980, I990 e, em menor escala, os anos 2000 tenham sido uma época difícil em termos de desenvolvimento econômico e níveis de desigualdade, mudanças institucionais extremamente importantes ocorreram no país. De uma forma geral, estas mudanças tiveram um efeito homogeneizador nos padrões de transição para vida adulta e, assim, agiram como forças opostas aos efeitos de heterogeneização das desigualdades e das crises econômicas. Dentre estas mudanças institucionais destaco quatro esferas que estão diretamente ligadas às transições para a vida adulta: sistema educacional, mer- 
cado de trabalho, família e políticas de proteção social. Do ponto de vista sociológico, a entrada na vida adulta é marcada por algumas instituições que regulam os ciclos de vida dos indivíduos. Estas instituições definem, muitas vezes, em que momentos as pessoas mudam alguns status importantes em suas vidas. Por exemplo, o sistema educacional define de forma mais ou menos padronizada com que idade os indivíduos podem deixam de frequentar a escola. O início da vida laboral também é regulado por leis que permitem ou não o trabalho de jovens e que incentivam ou não esse trabalho. Portanto, entender as características deste tipo de instituição é muito importante para analisar o processo de transição dos papéis sociais que se dá ao longo da juventude e que culmina com os indivíduos assumindo papéis sociais que são definidos como marcadores da vida adulta.

Foi a partir de 1982, quando ocorreram as primeiras eleições diretas para governadores depois do longo período de ditadura militar, que se iniciou um processo muito acentuado de expansão da educação básica no Brasil. De fato, aquelas eleições podem ser vistas como marcando um ponto de mudanças na política educacional brasileira. Muitos governadores eleitos por partidos de oposição ao regime militar iniciaram um grande esforço para construir mais escolas em seus estados. No Rio de Janeiro, em São Paulo e em Minas Gerais, os estados mais populosos da federação, a construção de novos prédios para as escolas foi rápida e bastante intensa. Mais importante do que isso, no entanto, foi o aumento proporcional do acesso de crianças e jovens à educação. Foi nessa época também que o problema da repetência como um empecilho para a progressão dos alunos no sistema educacional começou a ser detectado. Nos anos em que observei as duas coortes de idade que serão analisadas neste artigo (I996 e 2008), os jovens entre i 2 e 30 anos de idade estavam todos acima da idade de ter completado os quatro primeiros anos de escolaridade (a idade ideal para completar esse primeiro ciclo educacional é de ıo anos). De fato, em I996, cerca de $83 \%$ e, em 2008, cerca de 9I\% tinham completado os quatro primeiros anos de educação elementar e deveriam completar a educação básica (oito anos de estudo, ou primário completo) com I4 anos. No entanto, dos jovens com I4 anos ou mais, apenas $46 \%$, em I 996 , e $65 \%$, em 2008, haviam completado este nível educacional básico (8 ou 9 anos de educação). As taxas de repetência na educação básica no Brasil são extremamente elevadas (Klein \& Ribeiro, I99I). De fato, o problema da educação básica no país parecia não ser a falta de vagas, que justificava a construção de novas escolas, mas, sim, a repetência, que levava à progressão muito lenta dos estudantes dentro do sistema educacional (Klein \& Ribeiro, I99I).

Embora as altas taxas de reprovação levem um número elevado de jovens a não completar as oito séries de educação elementar, que são obrigatórias por lei, a proporção de crianças entre 5 e I4 anos de idade matriculada no ensino elementar cresceu constantemente. Por exemplo, em I985, 80\% 
destas crianças estavam matriculadas na escola e em 2000 o número já era de $95 \%$. Consequentemente, a matrícula no ensino médio (que ainda é optativo no Brasil) para jovens entre I5 e I9 anos de idade também aumentou de $22 \%$, em 1985, para $47 \%$, em 2000 . Legalmente é esperado que os estudantes permaneçam no sistema educacional até completarem I4 anos de idade, que também é a idade legal para iniciar atividades como aprendizes no mercado de trabalho. Assim sendo, é permitido que os estudantes combinem educação no ensino médio com participação no mercado de trabalho.

O sistema educacional brasileiro é caracterizado por um currículo básico comum para todas as escolas, ou seja, todas devem ensinar pelo menos o mesmo número básico de matérias e conteúdos. Na linguagem da sociologia da educação isso significa que o sistema educacional brasileiro é padronizado (Allmendinger, I989). ${ }^{2}$ Embora não haja estratificação oficial dentro do sistema educacional, a qualidade do ensino é muito diferente entre as escolas. Uma diferença básica é entre escolas públicas e privadas. Apenas algumas poucas escolas públicas são de boa qualidade, ao passo que o setor privado é muito diversificado, incluindo escolas muito baratas e de má qualidade, e outras muito caras e de boa qualidade. De qualquer forma, a comparação do desempenho dos alunos de escolas públicas e privadas indica que aqueles no setor privado têm em média um desempenho muito mais alto do que os no sistema público (Franco, 2007). Entre as décadas de I980 e 2000, um em cada dez estudantes estava matriculado em escolas privadas de ensino elementar. Em contraste, no ensino médio, três em cada dez estudantes estavam em escolas privadas. A maioria dos estudantes das escolas privadas de ensino elementar e médio são provenientes de famílias com status socioeconômico relativamente alto.

No ensino universitário a situação se inverte. As melhores universidades são públicas e não cobram mensalidades. Com a exceção de algumas poucas universidades (principalmente as Universidades Católicas), a grande maioria das instituições privadas é de má qualidade. Para entrar nas universidades os estudantes devem fazer exames de admissão, geralmente denominados de vestibular. Houve algumas mudanças ao longo dos anos, mas a ideia básica é que testes de conhecimento baseados no currículo do ensino médio são necessários para a entrada na universidade. Tendo em vista que as melhores escolas de ensino médio são privadas e as melhores universidades são públicas, é obvio que a organização do sistema educacional promove a desigualdade socioeconômica na entrada da universidade (Castro, I994). O padrão mais comum é o de estudantes com nível socioeconômico mais alto entrando em universidades públicas e estudantes mais pobres entrando em universidades privadas. Durante os anos I980 e I990, as matrículas nas escolas de ensino médio aumentaram sem que houvesse um aumento proporcional no ensino superior, o que criou uma espécie de gargalo para entrar na universidade. Nos anos 2000 essa situação começou a se modificar, tendo em vista 
que houve também um amento bastante significativo das matrículas no ensino superior. De fato, nos anos I99o houve um pequeno aumento da desigualdade de oportunidades para entrar na universidade (Ribeiro, 2009).

Como acontece em vários outros países da América Latina, o diploma universitário no Brasil tem um valor muito alto no mercado de trabalho e, em geral, equivale a retornos muito altos em termos de renda e status social. No entanto, o valor desses diplomas tem diminuído ao longo dos anos na medida em que se tornam menos escassos; esse fenômeno é denominado de "inflação de credenciais" e vem ocorrendo desde os anos I980 (Ferreira, 2006). Em contraste com países que têm ligação direta entre sistema educacional e mercado de trabalho - por exemplo, Alemanha e Suíça (Muller \& Shavit, I998) - o sistema educacional brasileiro não é baseado em uma ligação formal entre mercado de trabalho e educação de ensino médio. Ou, melhor dizendo, o número de escolas técnicas é muito pequeno e mesmo estas abrem a possibilidade de continuar os estudos depois de concluídas, ou seja, é sempre possível ir adiante e entrar na universidade.

Isso, contudo, não significa que o mercado de trabalho seja pouco regulamentado. Pelo contrário, o trabalho é altamente regulado para aqueles que estão no setor formal da economia. Para estes, várias regras devem ser seguidas, tais como: planos de pensão, idade legal para começar a trabalhar (I4 anos de idade), benefícios para desempregados, entre várias outras garantias trabalhistas. Nos anos I980 e I99o este mercado formal diminuiu e o mercado informal expandiu, tornando-se responsável por metade dos empregos nas áreas urbanas na década de 1990 (Cardoso, 2002). Na década de 2000 o mercado informal começou a diminuir, o que certamente é uma tendência positiva, embora este setor ainda seja muito grande no país. O mercado informal, como todos sabem, é completamente livre de regulamentações por parte do Estado. Empregados e trabalhadores por conta própria neste setor não têm nenhuma forma de direito trabalhista, embora frequentemente entrem em litígio para reivindicar estes direitos. Apesar desta falta de regulamentação, às vezes os retornos financeiros imediatos são maiores neste setor, tendo em vista que não há pagamento de impostos. A informalidade é obviamente ilegal, embora seja muito difícil trazer todos os trabalhadores para o setor formal. Há diversas discussões a este respeito com alguns autores sendo a favor de uma flexibilização do mercado de trabalho (Camargo, I996) e outros argumentando que a flexibilização seria uma política maléfica e geradora de desigualdades (Cardoso, 2000). Em geral, as grandes empresas têm mais dificuldade para contratar trabalhadores informais porque são mais regulamentadas e vigiadas, embora muitas vezes recorram a outras formas de remuneração que implicam menos impostos, tais como participação nos lucros, elaboração de cooperativas que na realidade não o são, e contratação de trabalhadores terceirizados (provenientes de outras empresas). 
O pouco crescimento econômico que caracterizou o país desde o início dos anos I980 não criou uma contração do mercado de trabalho, como era de se esperar. Neste período houve, inclusive, uma forte tendência de inclusão das mulheres no mercado de trabalho. Além disso, o desemprego nunca foi muito alto ao longo das três últimas décadas, alcançou seu patamar mais alto, de $9 \%$, nos piores anos da crise dos anos I980. O desemprego de jovens, no entanto, foi mais elevado e chegou a I3\% entre os jovens de I5 a 24 anos. Alguns estudos argumentam que o setor informal é o principal responsável pelas taxas baixas de desemprego, tendo em vista que sempre há a possibilidade de encontrar alguma forma de subemprego neste setor (Lam, I993).

Além do sistema educacional e do mercado de trabalho, há outra forma de organização social que influencia enormemente as transições para vida adulta. A família muitas vezes é pensada quase como uma segunda natureza, mas, de fato, é uma forma de organização social que se modifica muito ao longo do tempo e entre sociedades. Pense, por exemplo, no papel das mulheres nas famílias. Há algumas gerações muitas mulheres se dedicavam exclusivamente à família e não trabalhavam fora de casa. O divórcio, por exemplo, era altamente estigmatizado. Hoje em dia o papel das mulheres dentro e fora das famílias se modificou muito. Famílias extensas, em que pais, avós e filhos habitam a mesma residência, eram mais comuns antigamente. Essas e diversas outras formas de organização familiar estão relacionadas direta e indiretamente aos padrões de transição para a vida adulta. Embora várias modificações tenham ocorrido na organização familiar, o Brasil ainda é um país em que predomina a família nuclear. Segundo Goldani (2002), no ano de 2000 cerca de $70,9 \%$ da população vivia em famílias compostas por um homem e/ ou uma mulher, com ou sem filhos, I7,2\% viviam em famílias incluindo outros membros da família (como pais, tios etc.), 7,9\% viviam sozinhos, e $4 \%$ tinham algum outro tipo de arranjo familiar. Embora as famílias nucleares sejam predominantes, muitas famílias pobres ainda dependem de redes sociais e relações familiares de proteção. É comum vermos famílias pobres em que várias gerações e irmãos habitem o mesmo domicílio ou, pelo menos, domicílios contíguos. Em áreas pobres há frequentemente a possibilidade de fazer um "puxadinho" para abrigar um parente. Em geral domicílios multifamiliares são compostos por pais e seus filhos adultos que muitas vezes já são casados e já têm filhos (netos dos chefes de domicílio). Em suma, embora a fecundidade tenha diminuído, as famílias extensas ainda são comuns no Brasil (cerca de $17,2 \%$, em 2000).

Uma outra tendência importante na organização das famílias é a expansão do número de chefes de domicílio que são mulheres, principalmente por causa da taxa crescente de divórcios. Em I996, um em cada cinco domicílios $(20,6 \%)$ era composto por apenas uma mulher adulta (sem a presença de homens), e em 2008 esse percentual aumentou para $35 \%$. Além disso, hou- 
ve aumento significativo da participação de mulheres no mercado de trabalho: $63 \%$ delas estavam ativas em I980, e 74\% em 2000.3 A divisão do trabalho doméstico, no entanto, ainda é extremamente desigual, levando em conta que as mulheres fazem em média 2,5 vezes mais trabalhos domésticos que os homens (Goldani, 2002; Ribeiro, 2009).

Embora a taxa de fecundidade tenha caído para mulheres entre i5 e 49 anos de idade (4,4 em I980; 2,7 em I990; 2,4 em 2000, e I,9 em 2010), essa taxa para mulheres entre I5 e I9 anos de idade aumentou em $25 \%$ entre 1980 e 2000 (Berquó, 2004). A fecundidade de adolescentes se deve predominantemente a casos de mulheres jovens casadas com homens mais velhos do que elas e está inversamente relacionada a renda e educação (Aquino, 2003), ou seja, a fecundidade é maior entre as mulheres jovens mais pobres. De um modo geral, o declínio da fecundidade se deve a um maior conhecimento sobre métodos contraceptivos. Já em I996, por exemplo, 77\% das mulheres entre I5 e 49 anos de idade usavam algum método contraceptivo. O uso destes tipos de métodos está positivamente correlacionado aos anos de educação das mulheres, ao desejo de terem ou não filhos, ao acesso a atendimento de saúde, e à região de residência (no Sul e no Sudeste são mais usados) (Tavares, 2006). Entre as mulheres em idade reprodutiva, apenas $7,3 \%$ declararam ter tido filhos não desejados em ig96 (Tavares, 2006).

Os períodos de nascimento do primeiro filho, casamento e saída da casa dos pais são muito próximos no Brasil (Camarano, 2006). No entanto, também é comum que recém-casados vivam por algum tempo com os pais de um dos dois jovens, e quando estes casais jovens têm filhos as chances de residir com um dos sogros são ainda maiores. Estas tendências também variam consideravelmente de acordo com as condições socioeconômicas e a região do país, uma vez que a residência com os pais ou sogros é mais comum no Nordeste e entre famílias com renda mais baixa (Camarano, 2006).

Estas ajudas familiares são importantes, mas o Estado também tem instituições que podem melhorar as vidas dos mais necessitados. As políticas de proteção social no Brasil vêm se desenvolvendo muito desde o início dos anos 1980. A Constituição Federal de I988 criou condições legais para a expansão dos direitos sociais dos cidadãos. Hoje em dia todos têm direito a educação e saúde pública. O sistema de saúde pública, embora frequentemente criticado, melhorou enormemente no Brasil dos anos I970 para cá (Arretche \& Marques, 2002). Além disso, o Estado vem desenvolvendo políticas de transferência de renda que contribuíram para a diminuição das desigualdades ao longo dos anos 2000. Os jovens que estavam entrando na vida adulta entre as décadas de 1980 e 2000 o fizeram em uma sociedade extremamente desigual e numa economia em crise, mas também encontraram cada vez mais ao longo dos anos instituições que se fortaleciam e protegiam de alguma forma os cidadãos. Não há dúvida de que houve uma expansão da cidadania. 
A expansão do sistema educacional público ao longo deste período pode ser considerada como uma ampliação da cidadania e do estado de bem-estar social. Frequentemente, a criação de novas escolas veio acompanhada de serviços de saúde, merenda escolar etc. Nos anos I990 o governo também criou o Bolsa Escola, um programa de transferências financeiras para as famílias mais pobres condicionadas à matrícula das crianças nas escolas. Posteriormente, esse programa foi ampliado e passou a se chamar Bolsa Família. Estas políticas de transferência contribuíram para uma diminuição mais acentuada das desigualdades de renda ao longo da década de 2000 (Barros, 2006). Além disso, os programas de educação para jovens, que foram gradativamente implantados ao longo da década de 2000 , também podem ser vistos como políticas educacionais de proteção social na medida em que procuram capacitar jovens que se atrasaram no processo de aquisição de escolaridade.

Assim como algumas políticas educacionais têm caráter de políticas de bem-estar social, algumas iniciativas estatais no mercado de trabalho também podem ser vistas por este ângulo. No início da década de 1990 o governo começou a implantar alguns programas para integrar jovens no mercado de trabalho; estes, no entanto, foram considerados limitados porque atingiam apenas um número reduzido de jovens (Ramos, I997). Em contraste, a participação feminina no mercado de trabalho foi enormemente afetada pela Constituição de 1988. Mulheres empregadas no setor formal da economia têm direito a licença maternidade de I20 dias e não podem ser demitidas durante a gravidez. No entanto, mais da metade das mulheres trabalha no setor informal e não goza, portanto, destes benefícios. Além disso, famílias com crianças pequenas ainda encontram dificuldades de acesso a creches. Embora o número tenha aumentado ao longo dos anos (em 200I, 39\% dos domicílios com crianças com menos de 6 anos de idade tinham acesso a creches), a maioria das creches recebe crianças apenas durante uma parte do dia (manhã ou tarde). Assim, as famílias que têm crianças precisam recorrer a familiares e amigos para poder trabalhar fora de casa. Enquanto famílias pobres dependem dessa ajuda de familiares e amigos, famílias de classe média alta geralmente contratam babás e empregadas, o que facilita enormemente o trabalho dos pais. Como consequência destas situações, a participação no mercado de trabalho de mães com crianças pequenas é significativamente menor do que a participação de homens na mesma situação (Sorj, 2007).

Todas estas mudanças no sistema educacional, no mercado de trabalho, na estrutura familiar e nas políticas de bem-estar social que ocorreram entre as décadas de 1980 e 2000 se deram em uma sociedade extremamente desigual e num contexto econômico de crescimento muito baixo. É evidente que os altos níveis de desigualdade socioeconômica levam a padrões muito distintos de transição para a vida adulta nas esferas produtiva (trabalho e escola) e reprodutiva (casamento e maternidade) entre jovens mais pobres e mais ricos. 
A questão é saber como a desigualdade afeta estas transições; mais precisamente, é preciso responder a seguinte pergunta: como as transições vão variar entre as classes sociais tendo em vista o contexto histórico e demográfico, a estrutura das desigualdades, e as características institucionais descritas acima? Enquanto as desigualdades e as dificuldades econômicas estão diretamente ligadas a padrões heterogêneos de transição para a vida adulta, as melhorias no sistema educacional, no mercado de trabalho, na estrutura familiar e no estado de bem-estar social promovem a ampliação da cidadania e atuam como forças homogeneizadoras nos padrões de transição.

Em particular, as transições da escola para o mercado de trabalho para pessoas vivendo em áreas rurais e que ainda têm dificuldades de acesso à escola (às vezes é necessário viajar longas horas para chegar à escola) tendem a ocorrer mais cedo. O trabalho informal também é mais comum em áreas rurais, o que contribui para a entrada no mercado de trabalho mais cedo no ciclo de vida dos jovens. O setor informal do mercado de trabalho (aceitando ilegalmente o trabalho de jovens menores do que I4 anos) e a flexibilidade do sistema educacional (sempre é possível parar de estudar para trabalhar e depois voltar para a escola) facilitam a transição para o trabalho e a combinação entre trabalho e estudo cedo no ciclo de vida dos jovens. Ao comparar as duas coortes de nascimento, observadas em I996 e em 2008, imagino que estas transições na esfera produtiva ocorram mais tardiamente para a coorte mais nova justamente porque houve mais institucionalização ao longo do período estudado.

A estrutura das desigualdades no Brasil - com concentração no topo e menos desigualdade entre as famílias no meio e na parte inferior da distribuição de renda - provavelmente cria dois padrões distintos de entrada no mercado de trabalho: um, típico dos jovens no topo da hierarquia social e, outro, característico de jovens (no meio e embaixo da hierarquia social). Em outras palavras, os filhos cujos pais tinham educação de nível médio ou superior e ocupações de trabalho qualificado ou profissional provavelmente permanecem mais tempo na escola do que os filhos com origens sociais mais humildes. A principal diferença deve ser entre o topo e o resto. Além disso, minha expectativa é que essa desigualdade tenha diminuído entre a coorte mais velha e a mais nova porque, como indiquei acima, houve ampliação da cidadania ao longo das décadas de I980, I990, e 2000.

Na esfera reprodutiva, é possível que as famílias extensas tenham um impacto sobre os padrões de transição para o casamento e a maternidade. Nas famílias de classe baixa é comum que os recém-casados passem os primeiros anos de casamento na residência paterna ou materna. Além disso, jovens das classes baixas (casados ou não) com filhos pequenos também tendem a viver com seus pais. Em ambos os casos, diferenças de gênero devem prevalecer tendo em vista que os homens jovens casados ou com filhos pequenos são encorajados a entrar no mercado de trabalho. Em contraste, as mulheres jo- 
vens (sobretudo com filhos pequenos), estão mais propensas a se dedicar à vida doméstica. Jovens de classes mais altas estão mais propensos a permanecer solteiros por um período maior, a permanecer por longos períodos na casa dos pais, a constituir um lar independente apenas após o casamento, e a adiar ao máximo a primeira gravidez.

Por fim, espera-se que a idade tenha um importante impacto nos padrões de transição na esfera reprodutiva da vida. Nas décadas de I980, I990 e 2000 a rápida expansão dos benefícios sociais provavelmente exerceu efeitos homogeneizadores nos padrões de transição das coortes de idade estudadas nesse artigo. Estas mudanças institucionais adiaram as transições de todos os jovens para status da vida adulta. Ainda que tenha havido alguma homogeneização e padronização, a heterogeneidade dos padrões de transição influenciados pelas diferenças de classe provavelmente não foram eliminada. Tendo em vista que a expansão de direitos continuou a aumentar entre as décadas de 1980 e 2000 e que a desigualdade socioeconômica diminuiu a partir de meados dos anos I990, é possível que os padrões de transição para a vida adulta na esfera reprodutiva sejam menos heterogêneos na coorte mais nova (observada em 2008) do que na mais velha (1996). Havendo mais homogeneização ao longo dos anos, espera-se que apenas o efeito da idade seja importante ou, pelo menos, que se torne mais relevante ao longo dos anos. Caso não houvesse desigualdades, os padrões de transição para vida adulta seriam predominantemente determinados pela idade. Em outras palavras, indivíduos com diferentes origens socioeconômicas fariam as transições nos mesmos momentos do ciclo de vida, as diferenças seriam mais em termos de decisões pessoais e não relacionadas a grupos sociais de classe.

\section{DADOS E MODELOS \\ Dados}

As análises apresentadas aqui se utilizam dos dados da Pesquisa de Padrões de Vida (PPV) coletada em I996 e da Pesquisa Dimensões Sociais das Desigualdades (PDSD) coletada em 2008. A PPV é uma pesquisa domiciliar representativa das regiões Nordeste e Sudeste do Brasil e, assim, é representativa de $85 \%$ da população brasileira. Coletada entre I996-I997, 4 a PPV é uma amostra de 4.900 domicílios selecionada a partir de todos os domicílios que constituem a população brasileira. Informações sobre todos os indivíduos nas residências foram coletados e o número total de pessoas da amostra (crianças e adultos) é I9.400. A amostragem é baseada no Censo de I99I sobre a distribuição de municípios e "setores censitários" ("microrregiões no interior dos municípios"), e segue um procedimento de seleção probabilística. Primeiro, foram selecionados municípios, depois as microrregiões e, por fim, as residências no interior destas. Foram coletadas as informações de todas as pessoas (com 
Io anos ou mais) vivendo na residência. Este artigo restringe a análise aos homens e mulheres entre I2 e 30 anos para os quais há casos válidos para todas as variáveis utilizadas nas análises. Assim, a amostra contém informações para 4.905 indivíduos.

A "Pesquisa Dimensões Sociais das Desigualdades" (PDSD) é domiciliar e representativa da população brasileira, feita em todas as regiões, menos nas áreas rurais da região Norte. Coletada em 2008, a PDSD é uma amostragem probabilística e estratificada contendo 8.048 domicílios. Informações sobre todos os indivíduos nos domicílios foram coletadas e o número total de pessoas da amostra (crianças e adultos) é 26.I46. A amostragem segue procedimentos semelhantes aos da PPV e foi baseada no Censo de 2000. Com o objetivo de realizar análises comparativas com os dados de I996 (PPV), este artigo restringe a análise dos dados da PDSD (2008) aos homens e mulheres entre I 2 e 30 anos residentes no Nordeste e no Sudeste para os quais há casos válidos para todas as variáveis utilizadas nas análises, ou seja, a uma amostra de 3.064 indivíduos.

Utilizarei três variáveis dependentes marcando diferentes transições de status de entrada na vida adulta. Para estudar a transição da escola para o mercado de trabalho (transição no que defini como esfera produtiva da vida), defino uma variável com as seguintes categorias: (a) estuda; (b) trabalha e estuda; (c) trabalha; e (d) nem estuda, nem trabalha (nem, nem). Esta tipologia é particularmente importante para o Brasil, visto que é comum para os jovens combinarem escola e trabalho por causa tanto de necessidades econômicas quanto das características do sistema educacional que permite o retorno à escola em idades avançadas. Para estimar a probabilidade de estar em um destes quatro status - as transições condicionais - utilizo um modelo (regressão) "logit ordenado" com restrições. Os dados para homens e mulheres são analisados separadamente.

$\mathrm{Na}$ esfera reprodutiva, defino duas transições. A primeira, relacionada ao casamento e à criação de uma residência independente da dos pais, inclui as seguintes categorias: (a) filho solteiro (indivíduo que nunca se casou e nem saiu da casa dos pais, portanto, que não fez transição); (b) chefe casado (pessoa casada que seja chefe ou cônjuge do chefe de família, fez, portanto, duas transições: casou-se e formou um domicílio próprio); e (c) filho casado ou chefe de família (filho casado que vive no domicílio dos pais ou sogros, ou chefe solteiro, ou seja, indivíduo que fez, ao menos, uma transição: casamento ou domicílio próprio). Esta transição para um novo lar e/ou casamento é analisada separadamente para homens e mulheres. A segunda transição da esfera reprodutiva combina estado civil e maternidade, utilizando as seguintes categorias: (a) mulher sem filho; (b) mãe casada; e (c) mãe solteira. ${ }^{5}$ Apenas os dados para mulheres são analisados. Para analisar ambas as transições uso modelos logit ordenados com restrições. 
Em todos os modelos utilizei o mesmo conjunto de variáveis independentes, que procuram explicar as diferenças e desigualdades nos padrões de transição. A primeira é simplesmente a idade dos indivíduos (variando entre I 2 e 30 anos). As transições para a vida adulta estão fortemente relacionadas às idades e tendem a estar ainda mais se forem organizadas por instituições sociais relacionadas à idade. Por exemplo, o sistema educacional é uma instituição diretamente ligada à idade, tendo em vista que as pessoas frequentam a escola quando são crianças e jovens. Outras instituições, como o mercado de trabalho, também estão relacionadas à idade das pessoas. Caso não haja muita desigualdade socioeconômica, regional ou de área de residência, a idade tende a ser a principal variável correlacionada aos padrões de transição. Tendo em vista as tendências históricas que apresentei acima, é esperado que entre a coorte mais velha (I996) e a mais nova (2008) a idade seja cada vez mais importante para descrever os padrões de transição. A idade média das coortes era 2I,3 anos em I996 e 20,5 anos em 2008.

Além da idade, usei duas outras variáveis que se relacionam à área de residência. A primeira é a área (rural ou urbana) e a segunda a região (Nordeste ou Sudeste). Como mostro adiante, a residência em contextos urbanos ou rurais parece ser relevante para explicar alguns padrões de transição para a vida adulta. As regiões rurais são historicamente caracterizadas por níveis mais elevados de pobreza e desigualdade (Bacha \& Klein, 1989). A partir da década de I970, no entanto, a modernização da agricultura vem contribuindo para melhorar as condições de vida e as relações de trabalho nas áreas rurais, embora a desigualdade permaneça muito alta. Apesar da melhora relativa, a pobreza mais extrema ainda se encontra nas áreas rurais, principalmente nas regiões Norte e Nordeste. Em I996, os jovens entre I 2 e 30 anos de idade estavam concentrados majoritariamente em regiões urbanas (73\%), mas ainda havia uma proporção alta em regiões rurais (27\%). A tendência histórica de urbanização da sociedade brasileira continuou até 2008 , quando $82 \%$ dos jovens estavam em áreas urbanas e $18 \%$ em rurais. Tendo em vista a desigualdade histórica entre regiões urbanas e rurais no Brasil, é importante verificar se há diferenças significativas nos padrões de transição para a vida adulta destes jovens.

A desigualdade regional também pode ser uma característica da sociedade brasileira que influencia significativamente estes padrões de transição. Tendo em vista que a parte mais moderna e industrializada do país se encontra na região Sudeste, é importante levar em conta a desigualdade regional. Para as coorte de idade que uso para as análises apresentadas aqui, $44 \%$, em I996, estavam na região Sudeste, e 51\% estavam nesta região em 2008, enquanto $66 \%$, em I996, e $49 \%$, em 2008 , estavam na região Nordeste.

Além destas características geográficas (área e região de residência) utilizo uma variável para ocupação e outra para educação dos pais dos jovens. 
Estas duas variáveis medem as condições socioeconômicas e culturais das famílias em que os jovens cresceram. Na realidade, são as duas principais características usadas para descrever as desigualdades nos padrões de transição. Tendo em vista que as transições, tanto na esfera produtiva quanto na reprodutiva, estão relacionadas à saída da casa dos pais, é fundamental usar um banco de dados que contenha informações retrospectivas sobre as famílias em que os indivíduos cresceram. Para os indivíduos que ainda moram com seus pais é possível usar as características destes pais para medir o contexto familiar. Neste caso, diversas pesquisas domiciliares brasileiras (as Pesquisas Nacionais por Amostra de Domicílios - PNADs) contêm as informações relevantes. No entanto, quando os indivíduos não moram mais com seus pais (o que ocorre para $26 \%$ dos indivíduos da amostra utilizada para 1996, e $25 \%$ da amostra de 2008) não há informações para os pais dos indivíduos. Sendo assim, usar as PNADs leva a sérios problemas de seletividade, ou seja, se houver tendências de saída da casa dos pais relacionada às condições socioeconômicas de origem (como parece haver), as análises sobre transições para a vida adulta ficam seriamente comprometidas.

Nestes casos, a solução é usar dados retrospectivos, ou seja, dados provenientes de perguntas feitas para todos os chefes e cônjuges sobre a ocupação e educação de seus pais. Estes dados são os geralmente usados para definir a classe de origem dos indivíduos em estudos sobre mobilidade social (Ribeiro, 2007) e estão disponíveis para I996 (na PPV) e para 2008 (na PDSD). Estas duas pesquisas permitem combinar os dados dos chefes de família para definir a origem de classe (ocupação e educação dos pais) dos indivíduos (filhos) que ainda residem com seus pais com os dados retrospectivos (sobre os pais) dos indivíduos que já saíram da casa de seus pais. Esta combinação é fundamental para estudar os padrões de transição para a vida adulta e só pode ser feita quando há dados retrospectivos. Até onde vai o meu conhecimento, o presente artigo é o único contendo tais análises para a década de 2000 (2008).

Para classificar a ocupação dos pais dos indivíduos usei um índice de "status ocupacional" que hierarquiza todas as ocupações de acordo com os níveis típicos de renda e educação. Este índice (International Socioeconomic Index - ISEI) é amplamente utilizado na área de estratificação social (Ganzeboom \& Treiman, I996), e frequentemente interpretado como um indicador da renda permanente dos indivíduos, ou seja, a renda típica que obteriam em média ao longo de toda a sua vida. Mesmo que esta interpretação seja contestada, o ISEI é uma boa maneira de mensurar a hierarquia socioeconômica que diferencia as condições materiais de vida das famílias em que os indivíduos cresceram. Eu diria que este índice é uma maneira possível e plausível de mensurar o que as pessoas costumam chamar de classes sociais. O valor mais baixo de ISEI é I6, correspondendo à ocupação de trabalhador braçal sem 
qualquer qualificação, e o valor mais alto é 9o, correspondendo à ocupação de profissional de alto nível como, por exemplo, um juiz de direito ou dirigente de uma grande empresa.

Outra variável extremamente importante é o nível educacional dos pais dos indivíduos. Esta variável é normalmente interpretada como uma medida do que alguns sociólogos chamam de "capital cultural" (nível cultural de um indivíduo), mas também se relaciona às condições socioeconômicas, uma vez que educação está fortemente correlacionada à renda e à riqueza. Classifiquei a educação dos pais em cinco faixas: I) o a 3 anos de educação ou menos do que o antigo elementar completo (categoria de referência nos modelos; 2 ) 4 a 7 anos de escolaridade ou o antigo elementar completo; 3) 8 a io anos de escolaridade ou primário (novo elementar) completo; 4) II anos de escolaridade ou ensino médio completo; e 5) I 2 ou mais anos de escolaridade ou alguma educação de nível universitário ou mais. ${ }^{6}$

\section{Modelos}

Para analisar as transições para a vida adulta utilizei três variáveis dependentes: uma para transição da escola para o trabalho, outra para as transições para o casamento e o domicílio próprio, e uma terceira para as transições para a maternidade e o casamento. Para as duas primeiras variáveis analiso os dados para homens e mulheres separadamente, ou seja, estimo oito modelos: um para cada sexo para cada variável dependente (duas) para cada ano estudado (I996 e 2008). No caso da última transição analiso apenas os dados para mulheres (não há informações sobre o primeiro filho para os homens) usando dois modelos, um para cada ano. Ao todo estimo dez modelos incluindo as variáveis dependentes descritas acima (três) e as variáveis independentes também descritas (cinco).

Para estimar as probabilidades de transição condicional (em termos das variáveis independentes) utilizei um modelo chamado "partial proportional odds". Esse modelo pode ser considerado como intermediário entre o modelo logit ordenado e o modelo logit multinomial para variáveis dependentes categóricas nominais. Enquanto o modelo logit ordinal pressupõe que o efeito de cada variável independente é o mesmo na comparação entre todas as categorias ordenadas da variável dependente, o modelo logit multinomial pressupõe que o efeito varia para cada comparação. O modelo que usei é intermediário na medida em que faz testes para verificar quais variáveis independentes têm o mesmo efeito ao longo de todas as categorias da variável dependente (segue, portanto, a ideia de linhas paralelas entre categorias) e quais têm efeitos diferentes em cada categoria da variável dependente. Assim, o modelo é mais complexo do que o logit ordenado e menos complexo do que o logit multinomial, sendo, portando, de interpretação mais simples do que o 
modelo logit multinomial porque envolve a estimação de um número mais reduzido de efeitos.

No caso dos modelos que estimei para esse artigo, impus restrições para que algumas variáveis independentes tivessem o mesmo efeito em todas as categorias da variável dependente. Para impor estas restrições fiz testes estatísticos usando o programa gologit2 do STATA (William, 2006). Nas tabelas apresentando os modelos (Tabelas I, 2, e 3) as variáveis independentes que têm efeitos iguais (para as quais a restrição de efeito igual foi imposta) estão especificadas na parte definida como "restrições para linhas paralelas". As significâncias estatísticas dos testes individuais também são apresentadas, bem como um teste geral sobre a significância das restrições. Reparem que as variáveis para as quais a restrição é imposta têm o mesmo efeito ao longo de todos os contrastes da variável dependente.

\section{RESULTADOS}

\section{Transições na Esfera Produtiva}

De acordo com a Figura I, em I996, mais de 90\% dos homens e mulheres adolescentes estavam estudando ou combinando estudo com trabalho até os I4 anos, sendo que em 2008 mais de $90 \%$ estavam nestas duas alternativas até os I6 anos de idade. Em I996, este fato está relacionado tanto à obrigatoriedade dos anos de escolaridade (ou seja, 8 anos de educação primária até os I4 anos) quanto à idade legal para entrada no mercado de trabalho (também I4 anos). A ampliação da idade de I4 para I6 anos entre I996 e 2008 está ligada à expansão educacional, ou seja, ao fato de um percentual maior de jovens permanecer mais tempo no sistema educacional. Essa tendência é certamente positiva. Em I996, uma pequena parcela de mulheres e homens trabalha (ou combinam trabalho com escola), mesmo com menos de I4 anos, provavelmente porque no setor informal a idade legal para entrada no mercado de trabalho era frequentemente negligenciada. Na coorte mais nova, em 2008, praticamente não há jovens trabalhando antes dos I4 anos. Se a expansão do sistema educacional é responsável por uma grande parcela de jovens que permanecem na escola até os I4 anos, o setor informal, aliado ao período de estagnação econômica até meados da década de I990, trouxeram os jovens para o trabalho, forçando, assim, transições precoces para papéis sociais tipicamente adultos. Na década de 2000 , com mais institucionalização e menos desigualdade, houve uma mudança importante na medida em que não há jovens trabalhando até os I4 anos de idade.

Em 1996, diferenças de gênero passavam a ser mais pronunciadas por volta dos I5 ou I6 anos. Para as mulheres, a parcela apenas "estudando" e "nem estudando, nem trabalhando" aumenta constantemente até os 24 anos. Esta última categoria inclui uma grande parcela de mulheres dedicadas ao 
trabalho doméstico, seja porque já se casaram, seja porque ajudam com serviços domésticos na casa dos pais. Isto mostra que os papéis sociais desempenhados por mulheres após deixarem a escola (tipicamente aos I5 anos) estavam relacionados, em proporções semelhantes, ao mercado de trabalho e ao trabalho doméstico ("nem trabalham, nem estudam"). Em I996, o padrão para homens é bastante diferente. A partir dos I5 anos a proporção que apenas "trabalhava" aumentava constantemente de I2\% para $77 \%$ aos 24 anos. Em I996, aos 29 de idade praticamente todos os homens já estavam trabalhando, enquanto um pequeno percentual de mulheres ainda estudava e a grande maioria se dividia entre "trabalho" e a categoria "nem, nem" (que no caso das mulheres, como disse acima, significa majoritariamente trabalho doméstico e/ou casamento).

Entre 1996 e 2008 há mudanças bastante acentuadas nos padrões de transição da escola para o trabalho. Os padrões de transição de homens e mulheres se tornam muito mais parecidos na medida em que um percentual muito maior de mulheres passa a se dedicar somente ao "trabalho" - a proporção na categoria "nem, nem" diminui significativamente entre I996 e 2008. Outra mudança bastante evidente entre as coortes mais velha (I996) e mais nova (2008) é o aumento do tempo de permanência somente na escola ("estuda").

Apesar de todas estas mudanças positivas, há, para os homens, um percentual pequeno, mas que permanece praticamente inalterado entre I996 e 2008, que "nem estudam, nem trabalham". Esta situação inclui homens desempregados ou inativos, mas também alguns que correm risco de se envolver em atividades ilegais ou criminosas (Zaluar, 2004).

Em geral, os quatro gráficos da Figura I mostram grande heterogeneidade nas transições na esfera produtiva. Tanto para a coorte mais velha (I996) quanto para a mais nova (2008) há um grupo de homens e mulheres jovens que começam a trabalhar e deixam a escola com pouca idade, e outro grupo de jovens, bem menor, que consegue ficar na escola (provavelmente no ensino superior) até seus vinte e poucos anos. Para examinar se estes grupos de jovens são diferentes em termos de classe social de origem (ocupação e educação do pai) e residência (área e região) é fundamental observar os resultados dos modelos estimados e apresentados na Tabela I. Tendo em vista que a interpretação dos quatro modelos apresentados é complexa, apresento as probabilidades esperadas para dois perfis típicos de indivíduos.

As probabilidades esperadas são aquelas estimadas para pessoas que têm um determinado perfil definido pelas variáveis independentes incluídas no modelo. Apresento perfis para jovens em situações privilegiadas e desprivilegiadas em termos de origens socioeconômicas e culturais. O primeiro perfil é o dos jovens cujos pais tinham status ocupacional baixo (equivalente ao de um trabalhador manual não qualificado) e menos de quatro anos de escolaridade, e o segundo perfil é o dos jovens cujos pais tinham status ocu- 
pacional alto (equivalente ao de um profissional, por exemplo, médicos, advogados ou engenheiros) e educação superior. As probabilidades esperadas para estes dois perfis foram calculadas para as cinco faixas etárias incluídas nos modelos: I 2 a I4 anos de idade, I5 a I7 anos, I8 a 20 anos, 2I a 24 anos e 25 a 30 anos. As outras variáveis do modelo foram mantidas em seus níveis médios para calcular as probabilidades esperadas. Estes números revelam diferenças bastante significativas nos padrões de transição para a vida adulta entre os jovens com origem em classes altas e classes baixas. É importante ressaltar que os jovens de classe média, não apresentados, têm padrões de transição mais próximos dos jovens de classes baixas do que dos jovens de classes altas. Os dois perfis que defino estão relacionados aos seguintes efeitos de três variáveis (idade, educação dos pais, e ocupação do pai) incluídas nos modelos apresentados na Tabela I: quanto maior a idade dos jovens, maiores as chances de saírem da escola e começarem a trabalhar, e quanto mais altos a educação e o status ocupacional dos pais, menores as chances do filho ou filha deixar a escola e começar a trabalhar.

Para os homens com origens nas classes altas houve poucas mudanças entre 1996 e 2008. Em ambos os anos cerca de $90 \%$ ou mais dos homens até I7 anos de idade com origem de classe alta estavam apenas estudando; daí em diante o percentual diminui constantemente com a idade. Dos 18 aos 20 anos, entre $50 \%$ e $65 \%$ dos homes nos dois anos se dedicam apenas ao estudo, cerca de $20 \%$ combinam trabalho e estudo e $8 \%$ se dedicam apenas ao trabalho. Dos 2I anos em diante os homens passam a se dedicar crescentemente somente ao trabalho, o percentual que combina trabalho e estudo cresce até os 24 anos e começa a diminuir a partir dessa idade. A única diferença significativa entre 1996 e 2008 para os homens é o crescimento do percentual na categoria "nem, nem". É importante lembrar que os percentuais são obtidos a partir dos parâmetros estimados pelo modelo e, portanto, envolvem alguma variação devido à estimação. Provavelmente, a diferença entre as duas coortes é menor do que a aparente nas probabilidades esperadas. O que mais salta aos olhos é a não mudança nos padrões de transição para vida adulta dos homens jovens cujos pais eram profissionais e tinham educação universitária.

O padrão e as tendências de transição da escola para o trabalho das mulheres de classe alta são muito semelhantes aos dos homens. No entanto, há uma mudança significativa para estas jovens mulheres: o percentual na categoria "nem, nem" diminui e o percentual combinando trabalho e estudo aumenta entre I996 e 2008. Isso significa que as mulheres na coorte mais jovem (2008) se dedicavam mais ao trabalho e ao estudo e menos às atividades domésticas (categoria "nem, nem") do que as mulheres na coorte mais velha (I996). Essa é uma mudança significativa que afetou as mulheres cujos pais eram profissionais e tinham alguma educação universitária. 


\section{Homens 1996}

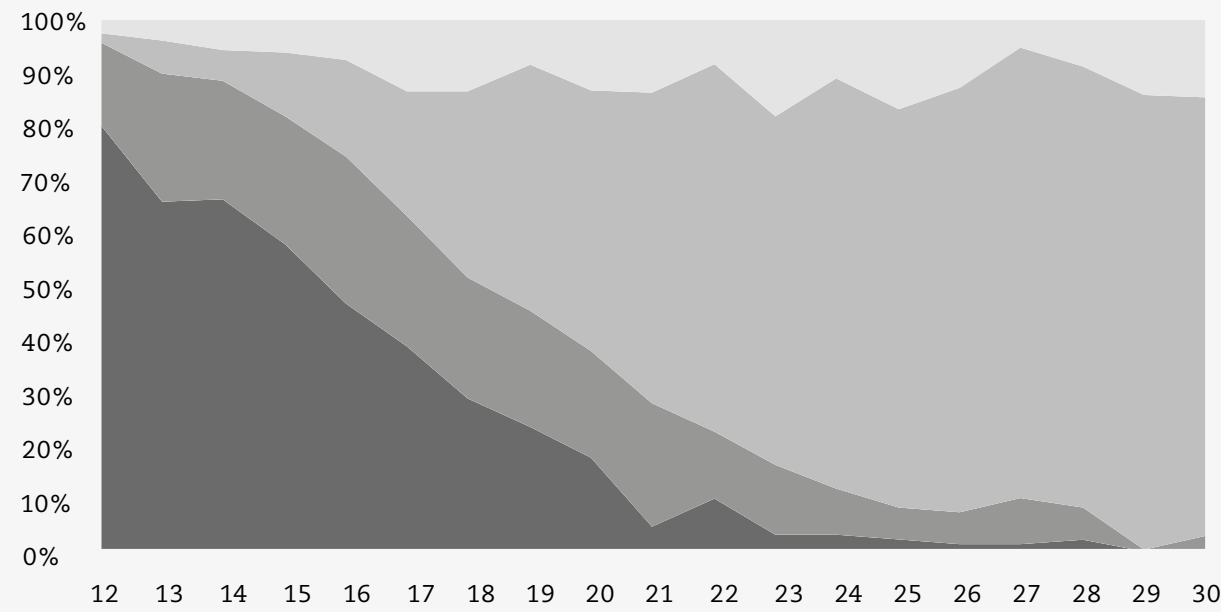

Homens 2008

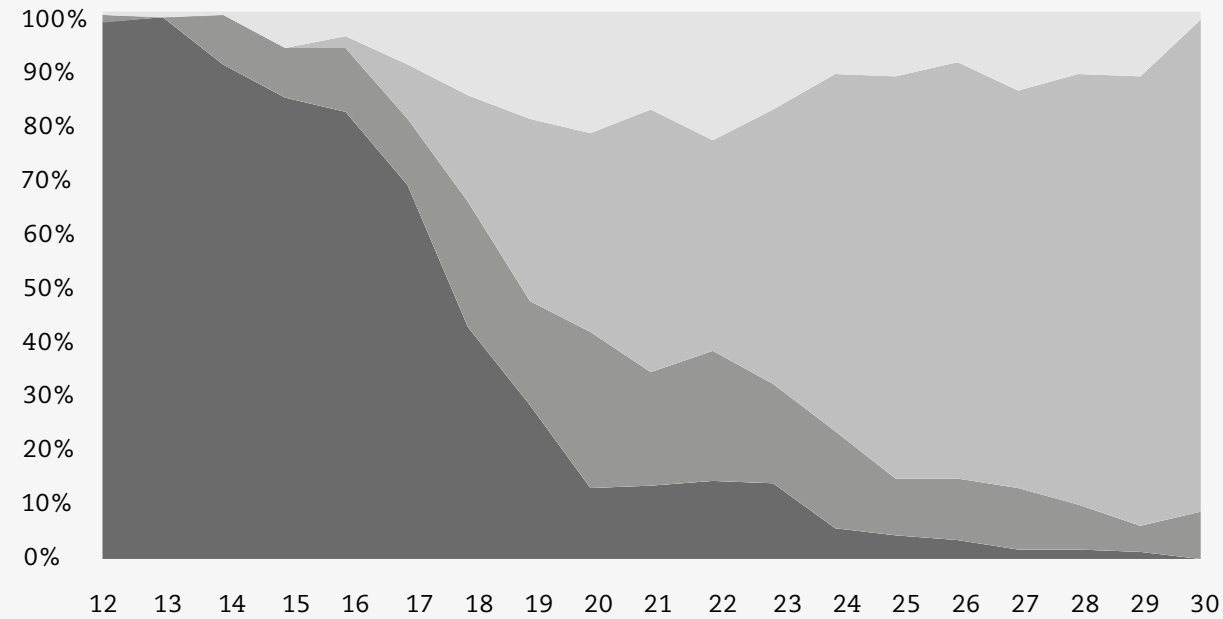

Estuda Estuda e trabalha Trabalha Nem trabalha, nem estuda 


\section{Mulheres 1996}

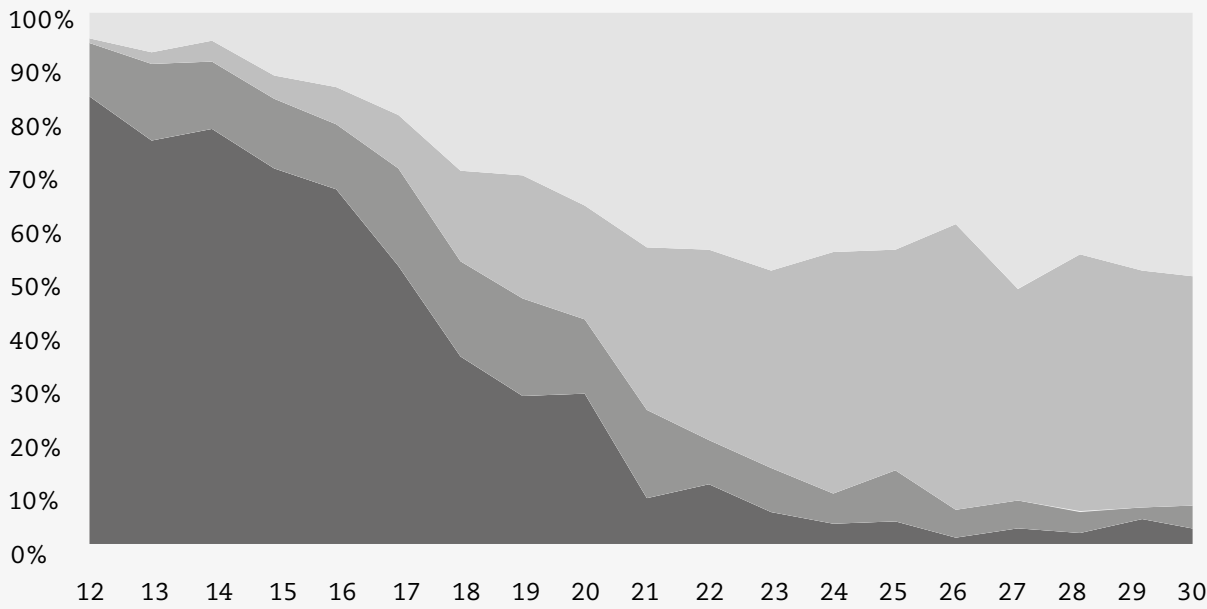

\section{Mulheres 2008}

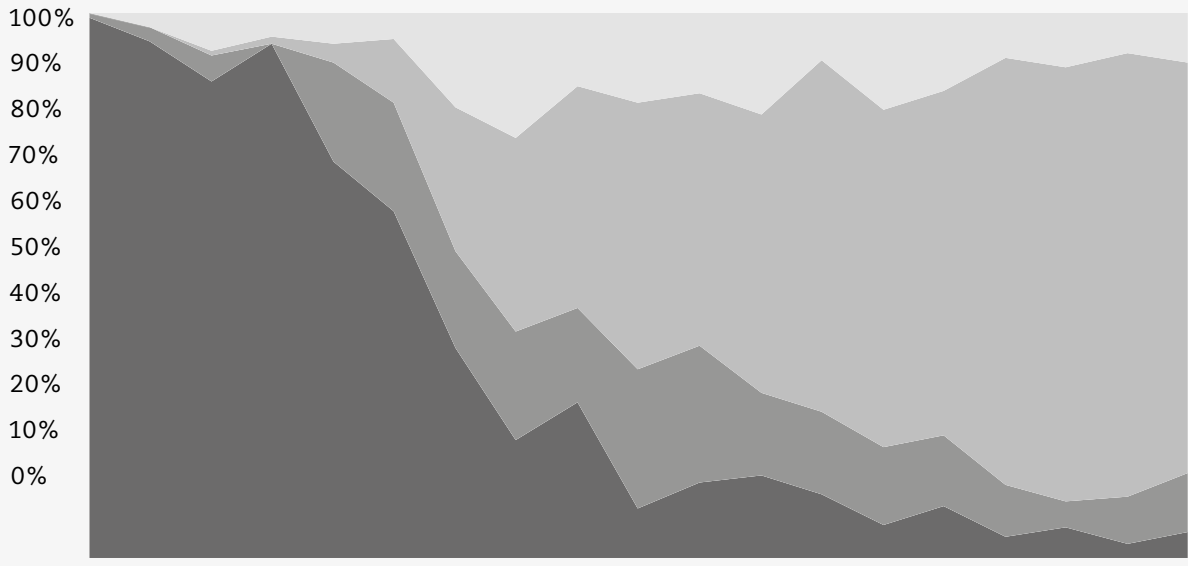

$\begin{array}{lllllllllllllllllll}12 & 13 & 14 & 15 & 16 & 17 & 18 & 19 & 20 & 21 & 22 & 23 & 24 & 25 & 26 & 27 & 28 & 29 & 30\end{array}$

Estuda Estuda e trabalha Trabalha Nem trabalha, nem estuda

Figura I.

Transições da escola para o mercado de trabalho por idade (I2 a 30 anos) e por sexo.

Brasil, I996 e 2008. 
Para homens e mulheres com origem nas classes baixas houve uma mudança muito significativa do percentual se dedicando apenas ao estudo. Em I996, 64\% dos homens e 74\% das mulheres entre i 2 e I4 anos se dedicavam apenas ao estudo, enquanto em 2008 esses percentuais passaram respectivamente para $92 \%$ e $94 \%$. Um aumento equivalente ocorreu para os jovens entre I5 e I7 anos: em I996, cerca de $34 \%$ dos homens e $54 \%$ das mulheres nessa faixa etária se dedicavam apenas ao estudo, percentuais que aumentaram em 2008 para respectivamente $67 \%$ e $76 \%$. Para os jovens de classes mais baixas houve realmente uma expansão do acesso ao sistema escolar que fez com que seus padrões de transição da escola para o trabalho se modificassem significativamente entre 1996 e 2008. A partir dos I8 anos o percentual de homens de classe baixa se dedicando apenas ao trabalho aumenta constantemente tanto em I996 quanto em 2008. Além disso, o percentual de homens de classe baixa combinando estudo e trabalho a partir dos I8 anos é sempre menor do que o percentual de homens de classe alta fazendo esta combinação. Em outras palavras, os homens de classe alta adquirem mais capital humano, tanto no sistema educacional quanto no aprendizado de trabalho combinado com o estudo.

Tanto em 1996 quanto em 2008 as mulheres de classe baixa tendem a ficar mais tempo no sistema educacional do que os homens de classe baixa. Há, entre 1996 e 2008, uma diminuição bastante significativa no percentual de mulheres de classe baixa que deixam de se dedicar a atividades domésticas (categoria "nem, nem") e passam a se dedicar ao mercado de trabalho (categorias "estuda e trabalha" e "trabalha"). Além disso, em I996 o percentual de mulheres de classe baixa na categoria "nem, nem" era muito mais elevado do que de mulheres de classe alta nessa categoria.

De um modo geral, as probabilidades estimadas pelo modelo revelam que a maioria de homens e mulheres de classes mais altas permanecem no sistema escolar até os 20 anos tanto em I996 quanto em 2008, enquanto a maioria dos homens e mulheres de classes mais baixas permanecem no sistema educacional até os I4, em I996, e até os I7 anos, em 2008. Houve uma melhoria para os jovens de classes mais baixas, enquanto os de classes mais altas continuam tendo vantagens em termos de acesso e permanência no sistema educacional. A transição para o trabalho se dá claramente em idades mais avançadas para os jovens de classe mais alta e, além disso, eles tendem a combinar mais estudo e trabalho e a evitar mais a inatividade (nem, nem).

Em 1996 há diferenças nos padrões de transição entre jovens vivendo em áreas urbanas e rurais, mas em 2008 essas diferenças não são estatisticamente significativas. De acordo com as probabilidades estimadas pelos modelos, em 1996 I9\% dos homens e $26 \%$ das mulheres em áreas urbanas tenderiam, em média, a estar apenas estudando, enquanto apenas $7 \%$ dos homens 
e I7\% das mulheres em áreas rurais estariam nesta situação. Para os homens também há uma maior tendência de trabalho, em vez de estudo, nas áreas rurais. Em outras palavras, tanto homens quanto mulheres em áreas urbanas (em I996) tinham mais chances de permanecer estudando ou combinando estudo e trabalho do que de se integrarem precocemente ao trabalho. Em contraste, a probabilidade de estar na situação de "nem trabalhar, nem estudar" em oposição a estar "trabalhando", ou "trabalhando e estudando", ou apenas "estudando", era maior nas áreas urbanas. Parece que no campo a possibilidade de estar na categoria "nem, nem" era bem menor do que nos centros urbanos. De um modo geral, as diferenças entre padrões de transição da escola para o trabalho em 1996 indicam que os jovens em áreas urbanas tinham mais chances de estudar por mais tempo. A situação nas cidades parecia melhor do que nas áreas urbanas. Tudo isso indica que os padrões de transição para o mercado de trabalho em 1996 eram muito diferentes entre as áreas rurais e as urbanas. Se os jovens urbanos tendiam a permanecer mais tempo na escola, aqueles em áreas rurais eram mais propensos a começar a trabalhar mais cedo. Dois fatores podem estar relacionados a esta diferença nos padrões de transição: primeiro, jovens em áreas rurais não conseguiam evitar a demanda por ajuda na pequena produção agrícola com a qual se ocupava a maior parte da população rural no Brasil (Goodman, I986); segundo, a escassez de escolas nas áreas rurais dificultava ainda mais a continuidade dos estudos dos jovens. Em 2008, estas diferenças não podem mais ser observadas, o que indica que a desigualdade entre áreas urbanas e rurais diminuiu ao longo dos anos. Isso provavelmente se deve à expansão tanto do ensino elementar quanto do médio que ocorreu ao longo dos anos I990 e 2000. A coorte mais jovem (2008) certamente se beneficiou desta expansão, que ainda era incipiente no momento em que a coorte mais velha (I996) estava fazendo a transição para o mercado de trabalho.

Alguns parâmetros estimados para a diferença entre as regiões Sudeste e Nordeste parecem ser relevantes, no entanto é muito difícil observar tendências temporais ou diferenças de gênero uma vez que os parâmetros não são estatisticamente significativos para os homens, em I996, e para as mulheres, em 2008. De um modo geral, os parâmetros indicam que há mais chances de homens, em 2008, e mulheres, em I996, que estivessem na região Sudeste de estarem trabalhando. Como não há tendências temporais ou de diferença de gênero nos mesmos anos é difícil interpretar o significado substantivo destes parâmetros estimados.

A análise das transições na esfera produtiva mostra padrões que são moldados por características institucionais, demográficas e estruturais descritas acima. O primeiro resultado importante está relacionado ao momento da transição para o mercado de trabalho. Minhas análises mostram que em I996 era, de fato, após os I4 anos que os jovens começavam a fazer as transi- 
ções para o mercado de trabalho e para fora da escola em grandes proporções. Este resultado está ligado ao fato de que I4 anos é a idade legal tanto para começar a trabalhar por remuneração quanto para terminar da educação obrigatória. Ainda que estas características institucionais expliquem a maior parte das taxas de entrada no mercado de trabalho e de saída da escola, em I996 uma proporção menor de jovens deixa a escola e entra no mercado de trabalho, provavelmente informal, antes dos I4 anos. Além disto, entre 1996 e 2008 há uma crescente porcentagem de jovens com I4 anos ou menos estudando e a idade típica para iniciar o trabalho aumenta para 16 anos. Estas tendências refletem a expansão contínua do sistema educacional que vem ocorrendo desde I982, mas que se acelerou ainda mais a partir de meados dos anos I990. A comparação de nossos gráficos com outros similares das décadas de 1970 e I980 (veja, por exemplo, Cardoso, 2008) revela uma expansão bastante significativa da matrícula de jovens nas escolas. Um segundo achado importante é que as condições socioeconômicas da família de origem (educação do pai e ocupação do pai) influenciam fortemente os padrões de transições da escola para o mercado de trabalho. Este padrão, que se mantém entre 1996 e 2008, está relacionado ao alto nível de desigualdade da sociedade brasileira. Embora a desigualdade tenha diminuído, os padrões de transição em termos de classe de origem permaneceram muito parecidos entre 1996 e 2008. Pais com ensino superior conferem uma vantagem especial a seus filhos e filhas; estes pais representam não apenas uma pequena parcela da população, mas também um segmento que possui níveis de renda significativamente mais elevados.

Uma característica surpreendente do padrão de transição da escola para o trabalho no Brasil é a parcela considerável de jovens que combinam escola com trabalho, que permanece muito alta entre I996 e 2008. O sistema escolar brasileiro permite que, a partir do ensino médio, os estudantes entrem e saiam da escola quando quiserem ou precisarem. Em outros países, uma vez que os estudantes abandonam o sistema educacional, é muito mais difícil que voltem a entrar nas escolas. No Brasil, em contraste, mesmo os jovens que não podem terminar a educação obrigatória por causa dos altos números de reprovação podem voltar a estudar em meio período ou em cursos especiais (há algum tempo esses cursos eram chamados de supletivos) de modo a concluir o ensino básico a qualquer momento. Em outras palavras, jovens que entram no mercado de trabalho - em tempo integral ou parcial - têm a chance de retornar para a escola para completar sua educação. No entanto, a entrada no mundo do trabalho antes da conclusão do ensino médio é um padrão comum para os jovens de famílias de classes mais baixas, mas muito improvável para aqueles criados na classe média alta. 


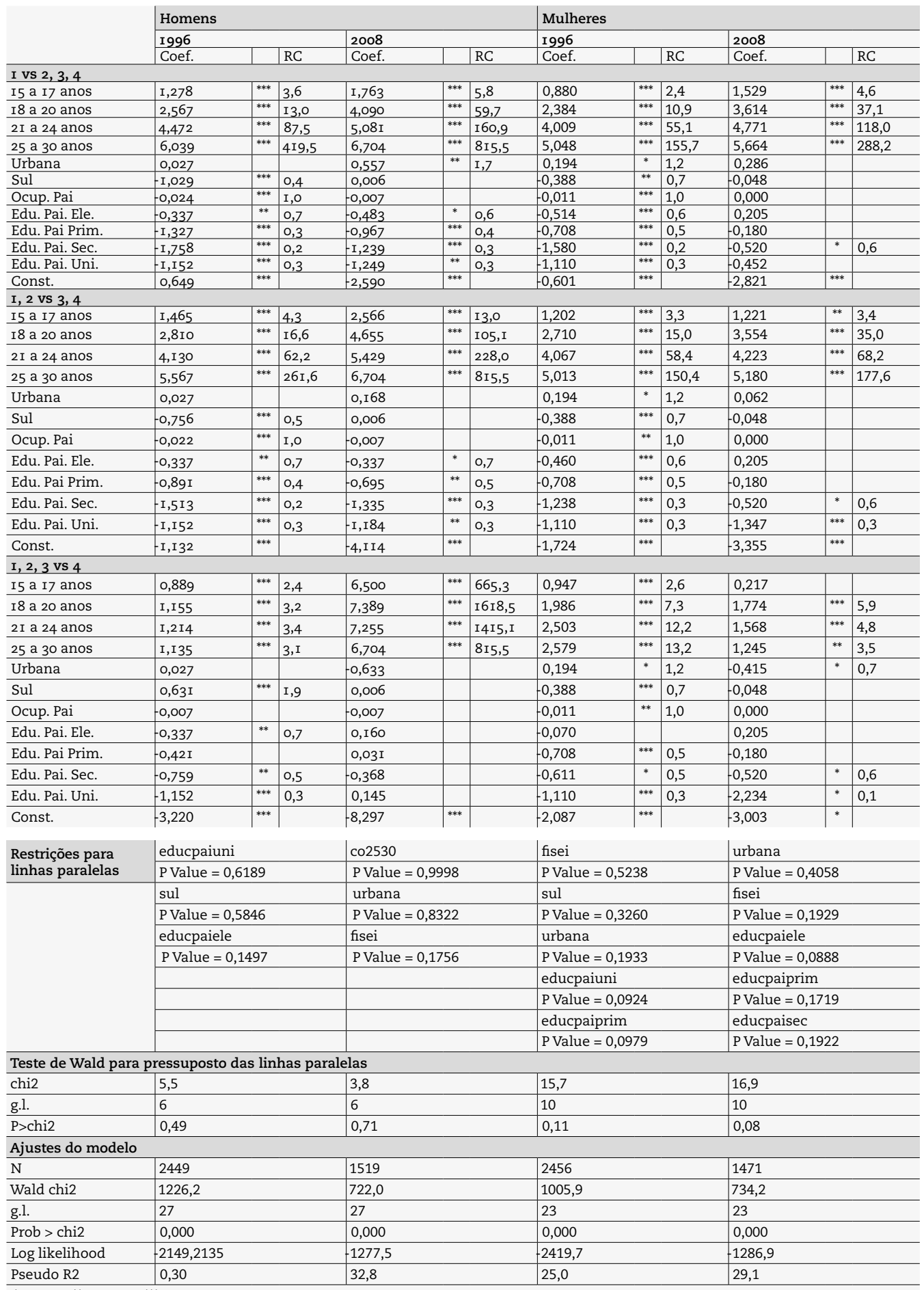

Tabela I.

Modelos estimados para transição da escola para o trabalho ( $\mathrm{I}=$ estuda, 2 = estuda e trabalha, $3=$ trabalha, e 4 = nem estuda, nem trabalha) para homens e mulheres entre I2 e 30 anos em I996 e 2008. 
DESIGUALDADES NAS TRANSIÇÕES PARA A VIDA ADULTA NO BRASIL (I996 E 2008)

458

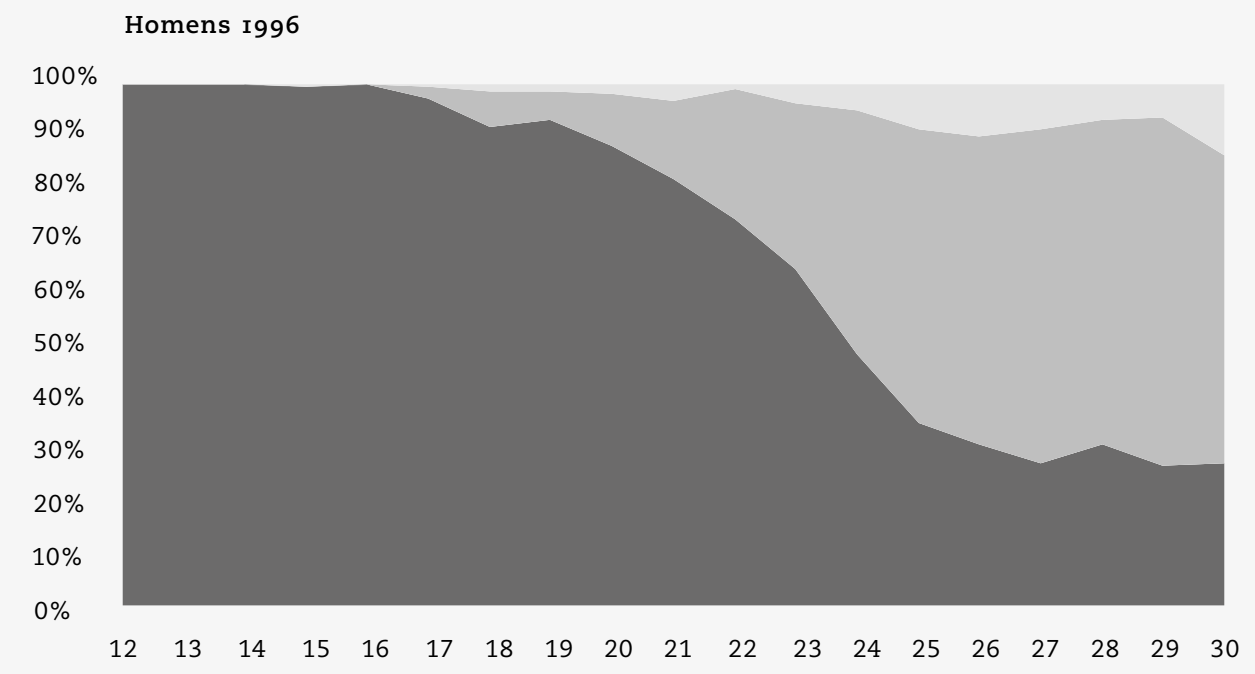

\section{Homens 2008}

$100 \%$

$90 \%$

$80 \%$

$70 \%$

$60 \%$

$50 \%$

$40 \%$

$30 \%$

$20 \%$

$10 \%$

$0 \%$

$\begin{array}{lllllllllllllllllll}12 & 13 & 14 & 15 & 16 & 17 & 18 & 19 & 20 & 21 & 22 & 23 & 24 & 25 & 26 & 27 & 28 & 29 & 30\end{array}$

Filho(a) solteiro(a) Chefe ou cônjuge casado Chefe solteiro 
Mulheres 1996

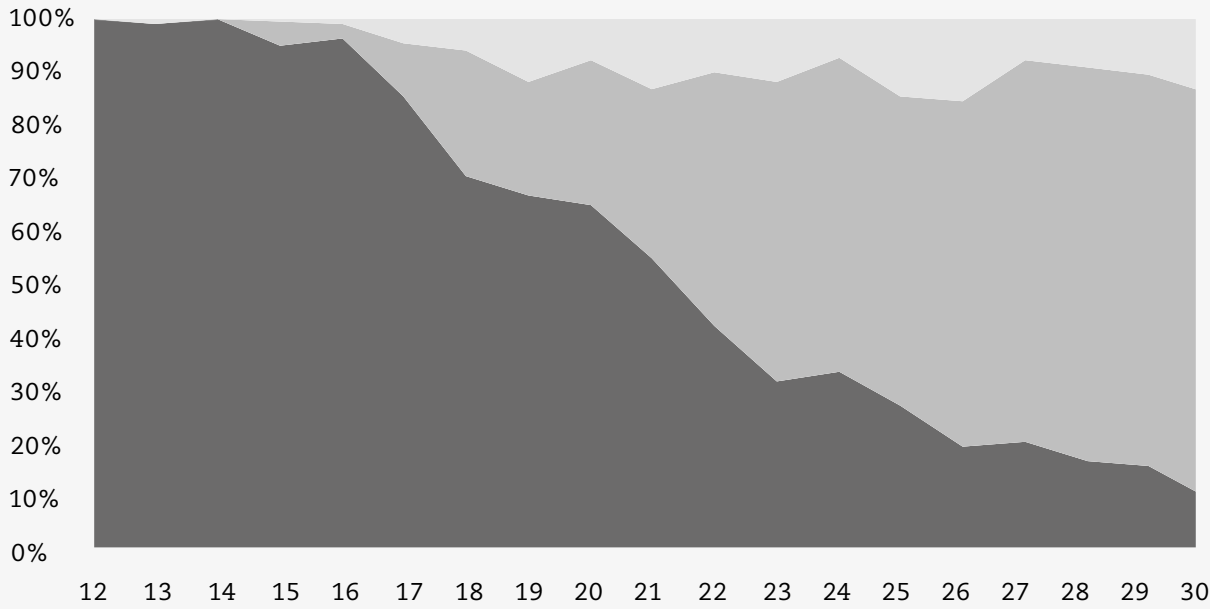

\section{Mulheres 2008}

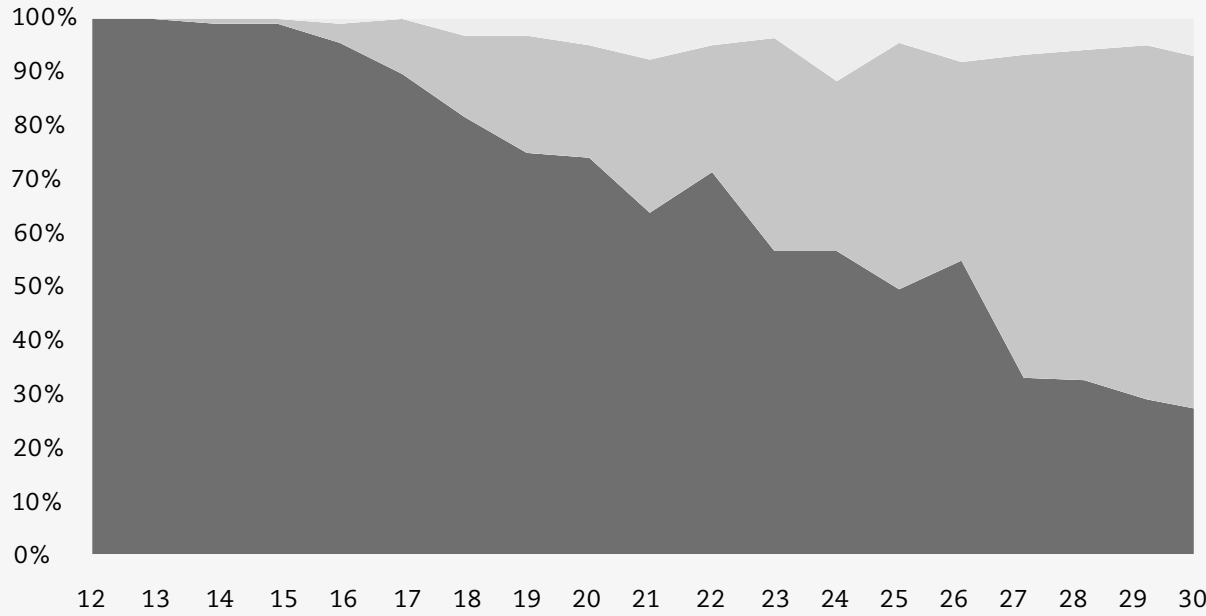

Filho(a) solteiro(a) Chefe ou cônjuge casado Chefe solteiro

\section{Figura 2.}

Transição para domicílio próprio e casamento por idade (I2 a 30 anos) e por sexo.

Brasil, 1996 e 2008. 


\section{Transições na esfera reprodutiva}

De um ponto de vista sociológico, a entrada na vida adulta envolve não apenas o início de uma carreira no mercado de trabalho, mas também o casamento, o estabelecimento de um lar independente e, eventualmente, o nascimento de filhos. Neste artigo defini estas últimas transições como aquelas relacionadas à esfera da vida reprodutiva, tendo em vista que casamento e maternidade implicam a reprodução ou criação de uma nova unidade familiar. No ciclo de vida da maioria das pessoas, casamento e maternidade ocorrem após a conclusão da escolaridade e a entrada no mercado de trabalho, mas em alguns casos estas mudanças de status podem ocorrer em ordens diferentes, ou seja, primeiro o filho, depois o casamento, depois o fim da escolaridade, ou qualquer outra ordem. No Brasil, a maioria das mulheres que se casam e dão à luz o fazem pouco após deixarem a escola.

Os gráficos da Figura 2 mostram os padrões de transição para o casamento e a residência própria de homens e mulheres jovens em I996 e 2008. Em ambos os anos as mulheres começam, em média, a se casar entre os 16 e os I8 anos de idade, e os homens entre os I8 e os 20 anos. Em I996, $24 \%$ das mulheres de 18 anos estavam casadas e/ou eram chefes de família ou cônjuges, enquanto apenas $6,4 \%$ dos homens encontravam-se nestas condições. Em 2008 , apenas $15 \%$ das mulheres e I,5\% dos homens com I 8 anos estavam casados ou eram chefes ou cônjuges. Os dados indicam claramente que os homens tendem a deixar a casa dos seus pais mais tarde que as mulheres. Dado que em 1996 as mulheres tendiam a se casar após deixarem a escola, elas também começavam a se dedicar majoritariamente às atividades domésticas ou ao trabalho remunerado a partir dos 18 anos de idade. Na verdade, a correlação entre as transições nas esferas produtiva e reprodutiva se modificou muito entre 1996 e 2008. Em I996, cerca de $60 \%$ das mulheres que eram casadas ou chefes de família "não trabalham, nem estudam", e cerca de $25 \%$ estava apenas trabalhando. Em 2008 estes percentuais passaram a ser 9,I\% das casadas na situação "nem, nem" e 9r\% apenas trabalhando.

De um modo geral, os gráficos da Figura 2 indicam que, entre 1996 e 2008, a saída da casa dos pais (a categoria "filho solteiro" representa aqueles que ainda moram com os pais) passou a ocorrer em idades mais avançadas do ciclo de vida dos jovens, ou seja, em 2008 os jovens permaneciam mais tempo na casa dos pais do que em I996. Esse padrão de transição varia um pouco de acordo com a classe social de origem (ocupação e, principalmente, educação dos pais), entre regiões urbanas e rurais, e entre o Sudeste e o Nordeste. Apesar destas diferenças, a principal variável determinando os padrões de transição da casa dos pais para o casamento e a casa própria é a idade dos jovens. Quanto mais velhos, maiores as chances de fazer a transição. 
Uso os mesmos perfis de jovens de classe alta e baixa descritos na seção anterior para apresentar os resultados dos efeitos de ocupação e educação dos pais nos padrões de transição para o casamento e/ou a residência própria (estes perfis foram construídos a partir dos parâmetros estimados pelos modelos apresentados na Tabela 2). Para homens e mulheres de classe alta - cujos pais tinham educação universitária e eram profissionais - não houve mudanças entre 1996 e 2008. Em ambos os anos, homens de classe alta começam a sair da casa dos pais ou a se casar entre os 18 e os 20 anos. $\mathrm{Na}$ faixa de 2 I a 24 anos, cerca de $20 \%$ já estão casados ou em casa própria, percentual que passa para $60 \%$ a partir dos 25 anos. Na faixa dos 2 I aos 24 anos de idade, cerca de $30 \%$ das mulheres de classe alta já estão casadas e $20 \%$ vivem fora da casa dos pais, mas não estão casadas. Entre os 25 e 30 anos 50\% estão casadas e $20 \%$ são solteiras e vivem fora da casa dos pais.

Para os jovens de classe baixa - cujos pais tinham menos de 4 anos de estudo e ocupação equivalente a trabalhador manual ou doméstico - houve algumas mudanças entre I996 e 2008. A principal mudança é que os padrões de transição daqueles com classe baixa e classe alta se tornaram mais semelhantes em 2008 do que eram em 1996. Homens e mulheres de classe baixa passaram a se casar e/ou a constituir domicílio próprio mais tarde no ciclo de vida. Outra diferença marcante é o fato de haver menos mulheres de classe baixa solteiras vivendo em residência própria. Enquanto $20 \%$ das mulheres com origens nas classes altas com mais de $2 \mathrm{I}$ anos eram solteiras e viviam sozinhas, menos de I0\% das mulheres com origens nas classes baixas estavam nessa situação. Esses dados indicam que as mulheres jovens com origem nas classes altas seguem padrões de transição para a vida adulta semelhantes aos observados em países desenvolvidos, ou seja, tendem a retardar o casamento e o eventual nascimento do primeiro filho. Isso significa que têm mais chances de desenvolver uma carreira profissional antes de começarem a criar uma nova família.

Apesar dessa diferença, houve, de um modo geral, uma equalização (em termos de classe de origem) dos padrões de transição para o casamento e a residência própria entre 1996 e 2008. Essas transições passaram a ser determinadas principalmente pela idade e deixaram de ser diferentes em termos de condições socioeconômicas e educacionais dos pais dos jovens. Embora os homens tendam a se casar mais tarde do que as mulheres, as diferenças de gênero também diminuíram significativamente em 2008, como pode ser facilmente observado nos gráficos da Figura 2. Em suma, os modelos indicam que em 2008 a transição para o casamento e/ou a residência própria começam a ocorrer entre os $2 \mathrm{I}$ e os 24 anos para os homens, e entre os $\mathrm{I} 8$ e os 20 anos para as mulheres. Em 2008, esses padrões são relativamente independentes da classe de origem e da região em que os jovens moram. 
A última transição que analiso neste artigo é o nascimento do primeiro filho. Os gráficos da Figura 3 apresentam as proporções de mulheres entre I2 e 30 anos de idade que não tinham filhos, que eram solteiras e tinham filhos, e que eram casadas e tinham filhos em 1996 e 2008 . Entre estes dois anos aumentou significativamente o percentual de mulheres que não tinham filhos e diminuiu o percentual de mulheres casadas com filhos, ao passo que o percentual de mães solteiras permaneceu praticamente inalterado. Em outras palavras, o efeito da idade na transição para a maternidade se modificou significativamente entre 1996 e 2008. De acordo com os modelos estimados (Tabela 3) o efeito da idade diminuiu, o que equivale a dizer que as transições para a maternidade passaram a se dar mais tardiamente no ciclo de vida das jovens.

Essa tendência geral é, no entanto, relativamente diferente entre mulheres de classe baixa e de classe alta, embora não haja diferença significativa entre 1996 e 2008 (ver parâmetros estimados, Tabela 3), a primeira diferença marcante diz respeito à condição de "mãe solteira", que se dá predominantemente nas classes baixas para ambas as coortes (I996 e 2008). Segundo as probabilidades estimadas pelos modelos, cerca de I0\% das mulheres de 18 anos ou mais com origens nas classes baixas tendem a ser mães solteiras, enquanto praticamente não há chances de mulheres com origens nas classes altas (cujos pais tinham curso universitário e eram profissionais) estarem na condição de "mães solteiras". As mulheres de classe baixa começam a ter filhos (casadas ou não) entre os I8 e 20 anos, enquanto as de classe alta passam a ter filhos somente entre os 2 I e os 24 anos. Em I996, a probabilidade de mulheres de classe baixa entre os 24 e 30 anos terem filhos é de 8 para ıo e, em 2008, de 7 para io. As probabilidades para mulheres de classe alta na mesma faixa etária são de 4 para ıo em I996, e de 3 para ıo em 2008. Em outras palavras, mulheres de classe alta têm maiores chances de adiar o nascimento do primeiro filho e de evitar o nascimento do primeiro filho sem que estejam casadas. Além disso, os modelos (Tabela 3) indicam que mulheres jovens no Nordeste e em regiões rurais têm mais chances de ter filho cedo e de serem mães solteiras em 2008 (para 1996 os coeficientes são estatisticamente significativos apenas para a região do país). Estes resultados são semelhantes aos encontrados em pesquisas anteriores (Berquó, 2005). Realmente, a maternidade na adolescência é um fenômeno que ocorre predominantemente nas classes mais baixas e nas regiões mais pobres do país. 


\section{Mulheres 1996}

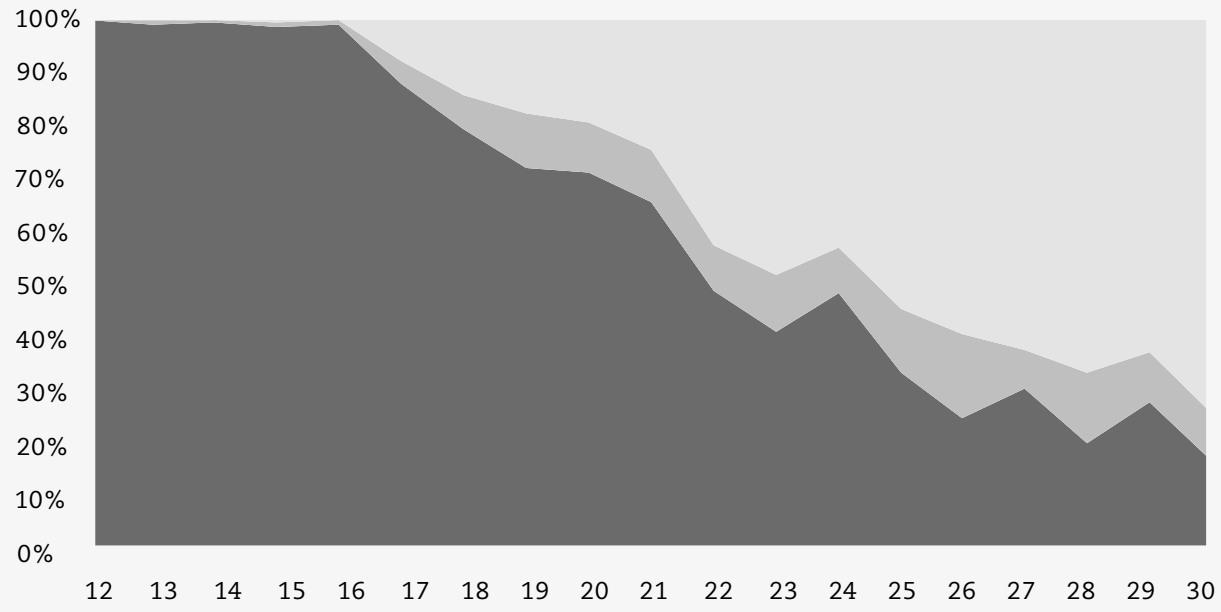

\section{Mulheres 2008}

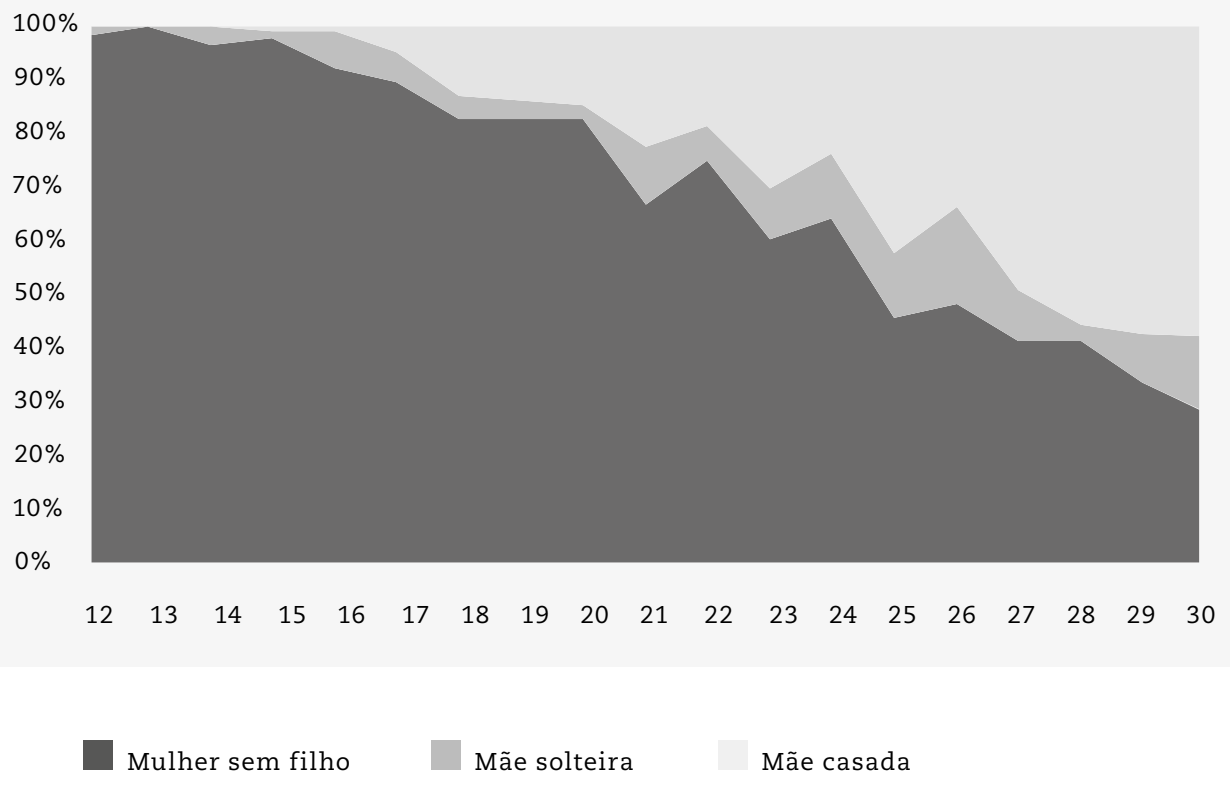

Figura 3.

Transição para a maternidade e casamento por idade (I2 a 30 anos) para mulheres.

Brasil, 1996 e 2008. 


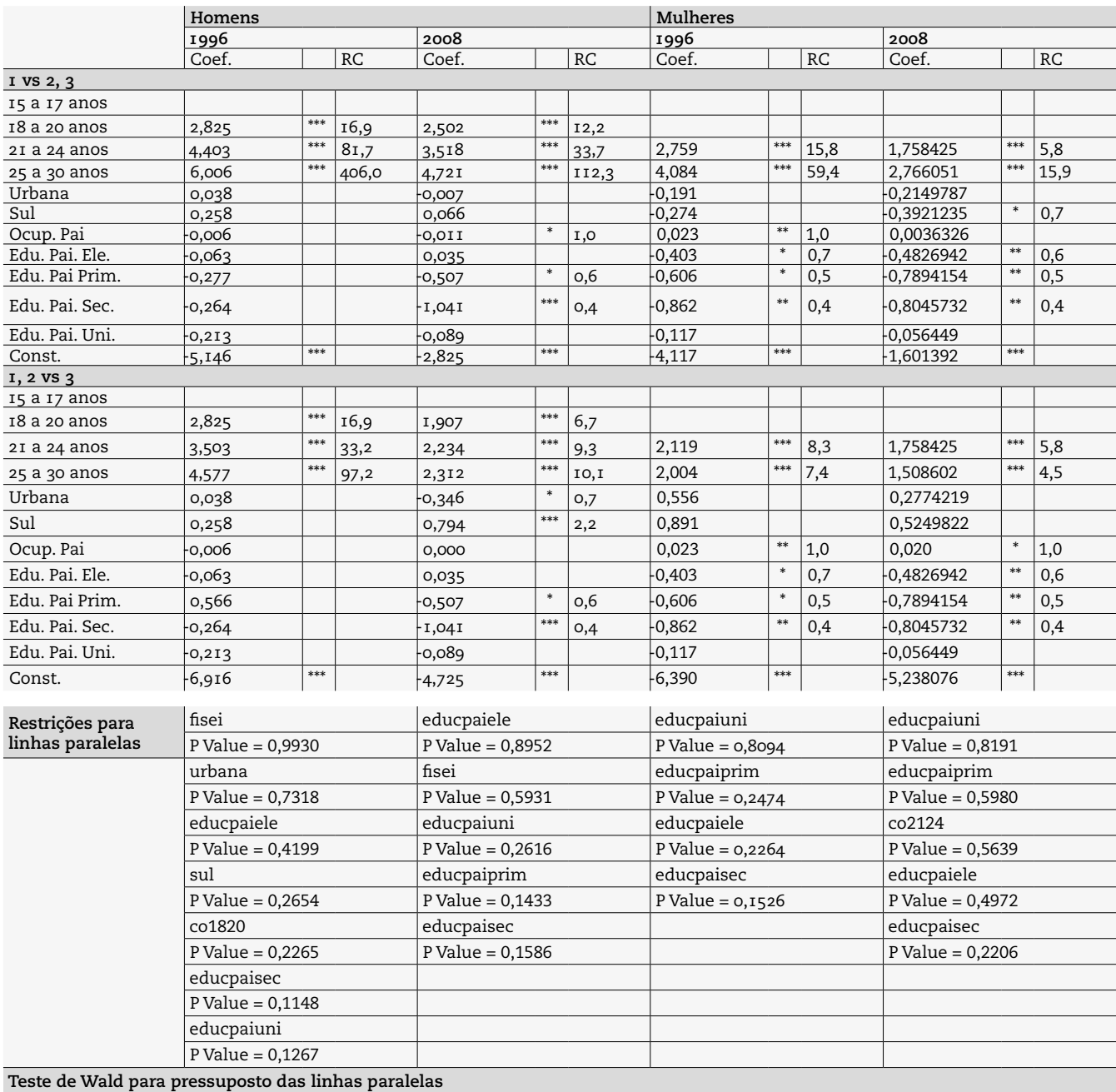

\section{Teste de Wald para pressuposto das linhas paralelas}

\begin{tabular}{|c|c|c|c|c|}
\hline chi2 & 8,1 & 5,2 & 4,8 & 2,7 \\
\hline g.l. & 7 & 5 & 4 & 5 \\
\hline P>chi2 & 0,33 & 0,39 & 0,31 & 0,75 \\
\hline \multicolumn{5}{|c|}{ Ajustes do modelo } \\
\hline $\mathrm{N}$ & 2449 & 1519 & 2456 & 1471 \\
\hline Wald chi2 & 462 & 290,2 & 709,4 & 334,3 \\
\hline g.l. & 13 & 13 & 16 & 13 \\
\hline Prob > chi2 & 0 & 0 & 0 & 0 \\
\hline Log likelihood & $-961,6$ & -643 & $-1420,6$ & $-847,3$ \\
\hline Pseudo R2 & 0,37 & 0,29 & 0,32 & 0,21 \\
\hline
\end{tabular}

${ }^{*} p<0,05 ;{ }^{* *} p<0,00 I ;{ }^{* * *} p<0,000$

Tabela 2.

Modelos estimados para transições para o casamento e o domicílio próprio ( $\mathrm{I}$ = filho solteiro, 2 =chefe ou cônjuge casado, e 3=chefe solteiro) para homens e mulheres entre I2 e 30 anos em I996 e 2008 . 


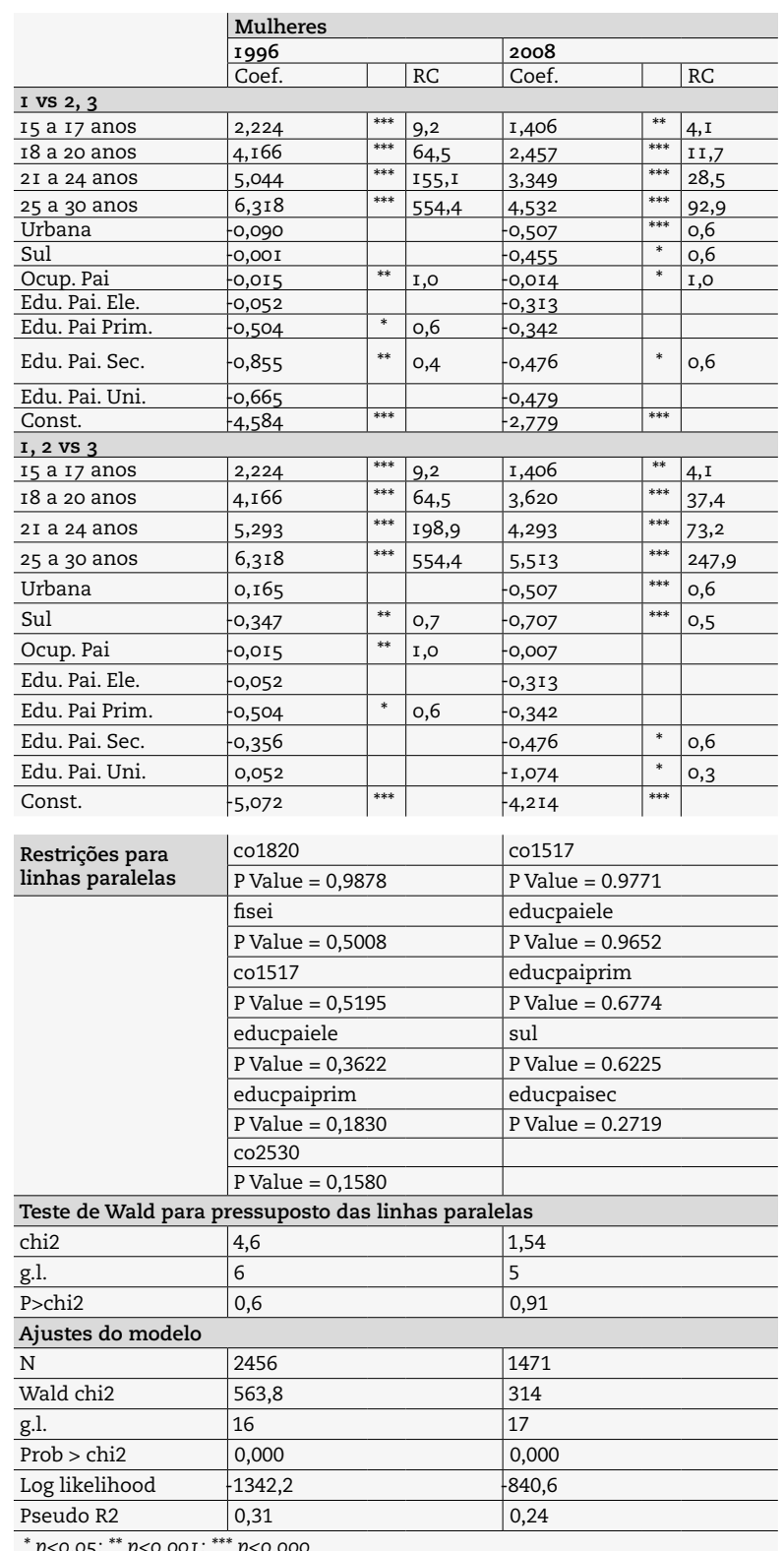

Tabela 3.

Modelos estimados para transições para o casamento e o primeiro filho ( $\mathrm{I}$ =mulhere solteira, 2 =mãe solteira, e 3=mãe casada) para mulheres entre I2 e 30 anos em I996 e 2008. 


\section{CONCLUSÕES}

No Brasil, as décadas de I980, I990 e 2000 caracterizaram-se por altos níveis de desigualdade e ausência de crescimento econômico, por um lado, e expansão dos direitos civis e acesso à educação, por outro. Na última década, 2000, também houve uma diminuição da desigualdade de renda. Crise econômica e desigualdade estão diretamente relacionadas a padrões heterogêneos de transição nas esferas produtiva e reprodutiva da vida. Ou seja, jovens com condições socioeconômicas mais elevadas tinham mais chances de ficar por mais tempo na escola, na casa dos pais, na vida de solteiros, e sem filhos; enquanto jovens de classes mais baixas tinham mais chances de fazer as transições para o trabalho, o casamento e a maternidade mais cedo em seus ciclos de vida.

Estes efeitos da desigualdade, no entanto, foram mediados e reduzidos por uma série de arranjos institucionais que predominaram e se desenvolveram no país desde a década de I980. O mais poderoso foi o acesso à escola, que afetou sobremaneira o momento das transições. A partir de meados da década de 1990, o fornecimento de vagas nas escolas aumentou de modo significativo. Esta mudança teve um enorme efeito nos padrões de entrada na vida adulta na medida em que diminuiu consideravelmente as diferenças de classe e gênero nas transições da vida produtiva e reprodutiva. Além disso, essas mudanças institucionais podem ser consideradas fatores importantes na própria diminuição das desigualdades econômicas. Os dados sobre transição para a vida adulta analisados nesse artigo indicam claramente que houve diminuição da desigualdade de classe de origem, de gênero, entre áreas rurais e urbanas, e entre o Sudeste e o Nordeste.

Estes resultados sugerem que a expansão dos direitos sociais (acesso a escola, regulação do trabalho, proteção trabalhista para as mães etc.) tiveram um forte impacto homogeneizador nos padrões de transição para a vida adulta, ou seja, as desigualdades de classe, de gênero e regionais nos padrões de transição diminuíram significativamente entre 1996 e 2008. Neste sentido, os padrões de transição dos jovens com origens socioeconômicas mais baixas foram os que mais se modificaram, tendo em vista que passaram a ser mais parecidos com os padrões de transição dos jovens de classes mais altas. O principal fator determinando essa equalização é a expansão do sistema educacional, embora as várias outras mudanças institucionais no mercado de trabalho também tenham contribuído para diminuir as diferenças nos padrões de transição.

Tendo em vista que não houve um aumento muito expressivo do crescimento econômico ao longo das décadas de I980, I990 e 2000 faz sentido concluir que as mudanças observadas se devem, principalmente, aos avanços institucionais que marcaram a história recente do país. Foram estes avanços 
que contribuíram para diminuir as desigualdades sociais e, consequentemente, as diferenças de classe, gênero, e região nos padrões de transição. Embora tenham diminuído, as desigualdades permanecem moldando padrões distintos de transição; em uma sociedade com menos desigualdade socioeconômica do que o Brasil, os padrões de transição seriam moldados principalmente pela idade e, em menor medida, por preferências individuais. O Brasil ainda está longe deste tipo de sociedade, mas os avanços institucionais dos últimos 35 anos ajudaram enormemente a diminuir as desigualdades nos padrões de transição. Tendo em vista que as tendências institucionais descritas continuam na mesma direção, há indícios de que os padrões de transição serão crescentemente determinados pela idade e cada vez menos pelas diferenças de classe. No entanto, este é um processo lento que depende muito mais da continuidade de certas políticas de Estado, como expansão dos direitos trabalhistas e educacionais, do que de políticas de um ou outro governo específico. Mudanças nos padrões de transição para vida adulta estão ligadas a mudanças geracionais que demoram muito para se materializar.

Recebido em I5/II/20I2 | Aprovado em 07/06/2014

Carlos Antonio Costa Ribeiro é doutor em Sociologia pela

Columbia University e professor do Instituto de Estudos

Sociais e Políticos da Universidade do Estado do Rio de Janeiro

(IESP-UERJ). Seu principal tema de pesquisa são os

determinantes da desigualdade de oportunidades econômicas

ao longo dos ciclos de vida e entre gerações. Neste sentido, estudou temas como mobilidade social, desigualdade de oportunidades educacionais, classes sociais, desigualdades raciais, mercados de casamento, e transições para a vida adulta. Seus livros mais recentes são Estrutura de classes e mobilidade social no Brasil (2007); Desigualdade de oportunidades no Brasil (2009), e Juventude, escola e trabalho (2014, no prelo). 


\section{NOTAS}

* Uma primeira versão deste artigo foi escrita em inglês e apresentada no Center for Advanced Study in the Social and Behavioral Sciences na Stanford University. Foi traduzido por Alexandre P. Ramos e em seguida acrescido de reformulações e atualização de dados, pelo autor [N.E.].

I Uma exceção é o estudo de Camarano (2006).

2 Até mesmo as poucas escolas técnicas de nível médio são obrigadas a seguir um currículo geral e, portanto, devem incluir matérias extras para cobrir o conteúdo técnico ou vocacional. Os alunos nestas escolas também podem concorrer a vagas na universidade, o que frequentemente fazem tendo em vista que as escolas técnicas públicas são de boa qualidade.

3 Dados para pessoas maiores de 9 anos de idade nos Censos de I980, 2000 e 2010.

4 O survey foi feito para coletar informações das regiões rurais durante períodos sazonais, e como consequência, residências rurais foram visitadas duas vezes para que se obtivessem informações econômicas relevantes destas áreas em períodos de colheita.

5 No entanto, deve-se mencionar que estas variáveis dependentes são limitadas ou "censuradas", isto é, alguns jovens entre 12 e 30 anos ainda não fizeram esta transição, mas virão a fazê-las eventualmente mais tarde.

6 É importante ressaltar que tomei os devidos cuidados para classificar os anos de educação, ou seja, dados referentes ao novo sistema que inclui 9 anos de estudo no ensino elementar foram compatibilizados com dados que se referem a apenas 8 anos de ensino primário. O primeiro ano dos 9 atuais corresponde à classe de alfabetização no sistema anterior.

\section{REFERÊNCIAS BIBLIOGRÁFICAS}

Allmendinger, Jutta. (1989). Educational system and labor market outcomes. European Sociological Review, 5/3, p. 23I-250. Aquino, Estela; Heilborn, Maria Luiza; Knauth, Daniela et al. (2003). Adolescência e reprodução no Brasil: a heterogeneidade dos perfis sociais. Cadernos de Saúde Pública, I9 (Sup. 2), p. 377-388. 
Arretche, Marta \& Marques, Eduardo. (2002). Municipalização da saúde no Brasil: diferenças regionais, poder do voto e estratégias de governo. Ciência e Saúde Coletiva, 7/3, p. 455-479.

Bacha, Edmar \& Klein, Herbert S. (1989). Socialchange in Brazil,1945-1985: the incomplete transition. Albuquerque: University of New Mexico Press.

Barros, Ricardo Paes de; Carvalho, Mirela de; Franco, Samuel \& Mendonça, Rosane. (2006). Uma análise das principais causas da queda recente na desigualdade de renda brasileira. Econômica, 8/I, p. II7-I47.

Barros, Ricardo Paes de; Tafner, Paulo; Carvalho, Mirela de \& Franco, Samuel. (2005). A olimpíada da incultura juvenil. Insight Inteligência, 29, p. I04-II4.

Berquó, Elza. (1998). Quando, como e com quem se casam os jovens brasileiros. In: Jovens acontecendo nas trilhas das políticas públicas. Brasília: Comissão Nacional de População e Desenvolvimento (vol. I).

Berquó, Elza \& Cavenaghi, Suzana. (2005). Increasing adolescent and youth fertility in Brazil: a new trend or a one-time event? Anais da Population Association of America: 2005 Metting. Filadélfia: Population Association of America, p. I-I8.

Berquó, Elza \& Cavenaghi, Suzana. (2004). Mapeamento socioeconômico e demográfico dos regimes de fecundidade no Brasil e sua variação entre I99I e 2000. Trabalho apresentado no XIV Encontro Nacional de Estudos Populacionais - ABEP. Caxambú, MG, 20-24 de setembro.

Brandão, Elaine Reis. (2006). Gravidez na adolescência: um balanço bibliográfico. In: Heilborn, Maria Luiza et al. (orgs.). O aprendizado da sexualidade: reprodução e trajetórias sociais de jovens brasileiros. Rio de Janeiro: Garamond/Fiocruz, p. 32-56.

Buchmann, Marlis. (1989). The script of life in modern society: Entry into adulthood in a changing world. Chicago: The University of Chicago Press.

Camarano, Ana Amélia. (2006). Transição para a vida adulta, ou vida adulta em transição? Rio de Janeiro: IPEA. 
Camarano, Ana Amélia \& El Gahouri, Solange Kanso. (2002). Famílias com idosos: ninhos vazios? Trabalho apresentado no XIII Encontro da Associação Brasileira de Estudos Populacionais - ABEP. Ouro Preto, MG, 4-8 de novembro. Cano, Inácio \& Ferreira, Carlos Eugênio. (2003). Homicídios e evolução demográfica no Brasil: o impacto da evolução demográfica na futura taxa de homicídios e a incidência dos homicídios na pirâmide populacional. In: Hasenbalg, Carlos A. \& Silva, Nelson do Vale (orgs.). Origens e destinos: desigualdades sociais ao longo da vida. Rio de Janeiro: Topbooks, p. 45-67.

Cardoso, Adalberto Moreira. (2002). Direito do Trabalho e relações de classe no Brasil. In: Vianna, Luiz Werneck (org.). A democracia e os três poderes no Brasil. Belo Horizonte: Ed. UFMG, p. IоI-I38.

Cardoso, Adalberto Moreira. (2000). Economia x Sociologia: eficiência ou democracia nas relações de trabalho? DADOS - Revista de Ciências Sociais, 43/I, p. I-33.

Castro, Claudio de Moura. (I994). Educação brasileira, consertos e remendos. Rio de Janeiro: Rocco.

Camargo, José Márcio. (I996). Flexibilidade e produtividade do mercado de trabalho brasileiro. In: Camargo, José Márcio (org.). Flexibilidade do mercado de trabalho no Brasil. Rio de Janeiro: Ed. FGV, p. 23-32.

Corseuil, Carlos Henrique; Santos, Daniel Domingues \& Foguel, Miguel Nathan. (200I). Decisões críticas em idades críticas: a escolha dos jovens entre estudo e trabalho no Brasil e em outros países da América Latina. Textos para Discussão, 797. Rio de Janeiro: IPEA.

Ferreira, Francisco H. G. et al. (2006). Ascensão e queda da desigualdade de renda no Brasil. Econômica, 8/I, p.I47-I69. Franco, Creso; Alves, Fátima \& Bonamino, Alícia. (2007). Quality of education in Brazil: policies, potentialities and limits. Educação e Sociedade, 28/ıoo, p. 989-IoI4.

Ganzeboom, Harry B. G. \& Treiman, Donald J. (I996). Internationally comparable measures of occupational status for the I988 International Standard Classification of Occupations. Social Science Research, 25, p. $201-239$. 
Goldani, Ana Maria. (2002). Família, gênero e políticas: famílias brasileiras nos anos 90 e seus desafios como fator de proteção. Revista Brasileira de Estudos Populacionais, I9/I, p. 29-48.

Goodman, David. (I986). Economia e sociedade rurais a partir de 1945. In: Bacha, Edmar \& Klein, Herbert (orgs.). A transição incompleta: Brasil desde 1945. Rio de Janeiro: Paz e Terra, p. 72-89.

Hasenbalg, Carlos Alfredo. (2003). A transição da escola para o mercado de trabalho. In: Hasenbalg, Carlos A. \& Silva, Nelson do Valle (orgs.). Origens e destinos: desigualdades sociais ao longo da vida. Rio de Janeiro, Topbooks, p. 23-4I.

Hasenbalg, Carlos \& Silva, Nelson do Valle (I988). Estrutura social, mobilidade e raça. Rio de Janeiro: IUPERJ/Vértice.

Kerckhoff, Alan C. (I990). Getting started. Oxford: Westview Press.

Klein, Ruben \& Ribeiro, Sergio Costa. (1997). A pedagogia da repetência ao longo das décadas. Avaliação e Políticas Públicas em Educação, 3/6, p. 55-6I.

Klein, Ruben \& Ribeiro, Sergio Costa. (I99I). O censo educacional e o modelo de fluxo: o problema da Repetência.

Lam, David \& Schoeni, Robert. (I993). Effects of family background on earnings and returns to schooling: evidence from Brazil. Journal of Political Economy, IoI/4, p. 710-740.

Madeira, Felícia \& Bercovich, Alícia. (I992). A "onda jovem" e o seu impacto na população economicamente ativa de São Paulo. Planejamento e Políticas Públicas, I/8, p.I-28.

Oliveira, Elzira Lúcia de; Rios-Neto, Eduardo Gonçalves \& Oliveira, Ana Maria. (2006). Transições dos jovens para o mercado de trabalho, primeiro filho e saída da escola: o caso brasileiro. Revista Brasileira de Estudos Populacionais, 23/I, P. IO9-I 27.

Ramos, Lauro \& Reis, José Guilherme Almeida. (I997). Emprego no Brasil nos anos 9o. Texto para Discussão, 0468, Rio de Janeiro: IPEA.

Ribeiro, Carlos Antonio Costa. (2009). Desigualdade de oportunidades no Brasil. Belo Horizonte: Argvmentvm. 
Rocha, Sonia. (2003). Pobreza no Brasil: afinal, de que se trata? Rio de Janeiro: Ed. FGV.

Silva, Nancy \& Kassouf, Ana Lúcia. (2002). A exclusão social dos jovens no mercado de trabalho brasileiro. Revista Brasileira de Estudos Populacionais, I9/2, p. 99-II5.

Silva, Nelson do Valle. (1987). Distância social e casamento inter-racial no Brasil. Estudos Afro-Asiáticos, I4, p. 54-83.

Silva, Nelson do Valle \& Hasenbalg, Carlos Alfredo. (1992). Relações raciais no Brasil contemporâneo. Rio de Janeiro: Rio Fundo.

Sorj, Bila; Fontes, Adriana \& Machado, Danielle Carusi. (2007). Políticas e práticas de conciliação entre família e trabalho no Brasil. Cadernos de Pesquisa, 37/132, p. 573-594. Tavares, Luciane Santiago. (2006). Demanda total por anticoncepção no Brasil: uso e necessidade insatisfeita por métodos anticoncepcionais. Tese de doutorado/Escola Nacional de Saúde Pública Sérgio Arouca. Rio de Janeiro, Fundação Oswaldo Cruz.

Telles, Edward E. (2004). Race in another America: the significance of skin color in Brazil. Princeton: Princeton University Press.

Wajnman, Simone; Lanza, Bernardo; Queiroz, Vania \& Liberato, Cristina. (I998). O crescimento da atividade feminina nos anos noventa no Brasil. In: Anais do XI Encontro Nacional de Estudos Populacionais, p. 13-36.

Williams, Richard. (2006). Generalized ordered logit/partial proportional odds models for ordinal dependent variables. The Stata Journal, 6/I, p. 58-82.

Zaluar, Alba. (2004). Integração perversa: pobreza e tráfico de drogas. Rio de Janeiro: Ed. FGV. 


\section{Palavras-chave \\ Desigualdades sociais; \\ Transições para \\ vida adulta; \\ Escola e trabalho; \\ Casamento; \\ Fecundidade.}

Keywords

Social inequality;

Transitions to

adulthood;

School and work;

Marriage;

Fertility.

\section{DESIGUALDADES NAS TRANSIÇÕES}

PARA A VIDA ADULTA NO BRASIL (1996 E 2008)

\section{Resumo}

Este artigo analisa desigualdades nas transições para a vida adulta no Brasil nas décadas de 1990 e 2000. Três transições são analisadas: saída da escola e entrada no mercado de trabalho, casamento e formação de um domicílio independente, e nascimento do primeiro filho. As análises apresentadas indicam que houve uma diminuição das desigualdades socioeconômicas nos padrões de transição, ou seja, a diferença nos padrões de transição de jovens cujos pais tinham condições socioeconômicas distintas diminuíram. A principal força equalizadora foi a expansão do sistema educacional que ocorreu ao longo das décadas de I980, I990 e 2000. As diferenças de gênero também diminuíram. Apesar destas mudanças ainda há fortes desigualdades relacionadas ao momento do ciclo de vida em que os jovens fazem as transições.

\section{INEQUALITY IN TRANSITIONS TO}

\section{ADULTHOOD IN BRAZIL (1996 AND 2008)}

\section{Abstract}

This paper analyzes inequalities in the transitions to adulthood in Brazil between the I990's and the 2000's. Three status exchanges are studied: transition from school to work, transition from parents' household to marriage and own household, and transition into motherhood. The analysis presented reveal that there was a diminishment of socioeconomic inequality in patterns of transition, that is, the difference in patterns of transition among youths whose parents had different socioeconomic conditions diminished. The main equalizing force was the educational expansion during the decades of the I980's, I990's and 2000's. Gender differences also diminished. Despite all these changes strong inequalities related to the moment in the life cycle in which youth make the transitions remain significant. 